Portland State University

PDXScholar

Master of Environmental Management Project

Reports

Environmental Science and Management

Spring 2003

\title{
Watershed Data Organization and Project \\ Prioritization
}

Joshua Darling

Portland State University

Follow this and additional works at: https://pdxscholar.library.pdx.edu/mem_gradprojects

Part of the Environmental Indicators and Impact Assessment Commons, and the Natural Resources Management and Policy Commons

Let us know how access to this document benefits you.

\section{Recommended Citation}

Darling, Joshua, "Watershed Data Organization and Project Prioritization" (2003). Master of Environmental Management Project Reports. 2.

https://pdxscholar.library.pdx.edu/mem_gradprojects/2

https://doi.org/10.15760/mem.38

This Project is brought to you for free and open access. It has been accepted for inclusion in Master of Environmental Management Project Reports by an authorized administrator of PDXScholar. Please contact us if we can make this document more accessible: pdxscholar@pdx.edu. 


\title{
WATERSHED DATA ORGANIZATION AND PROJECT PRIORITIZATION
}

\author{
A Masters Project Presented \\ By \\ JOSHUA DARLING
}

\begin{abstract}
Submitted to the
Department of Environmental Science and Resources

at Portland State University and Oregon Department of Forestry

in partial fulfillment of the requirements for the degree of

Master of Environmental Management
\end{abstract}

May 2003 


\section{Table of Contents}

1. Introduction 3

2. Identifying Watersheds Containing State Forest Lands 6

3. Data Assessment \& Collection 12

3.1. Overview 12

3.2. Data Standards 13

3.3. Data Identification \& Collection $\quad 19$

3.4. Data Gaps 25

3.5. Other Data 27

4. Data Organization 30

5. Watershed Prioritization $\quad 32$

5.1. Overview 32

5.2. Screen 1

5.2.1. Description 34

$\begin{array}{lll}\text { 5.2.2. Techniques } & 37\end{array}$

5.3. Screen 2

5.3.1. Description 43

5.3.2. Techniques 43

5.4. Screen 3

5.4.1. Description 45

5.4.2. Techniques 48

5.5. Future Priorities 49

5.6. Limitations of the Prioritization Models 53

6. Conclusion 55

7. References $\quad 57$

Appendix A: Table of fifth-field watersheds containing state forestlands $\quad 58$

$\begin{array}{ll}\text { Appendix B: OWAM data requirements matrix } & 61\end{array}$

Appendix C: Watershed Database Users Manual

Digital Appendix:

Watershed Database, Documents, GIS Digital Map Layers, Report 


\section{INTRODUCTION}

The Oregon Coastal Salmon Restoration Initiative (OCSRI) (1997) is the first of several documents that have come to be known as the Oregon Plan for Salmon and Watersheds (OPSW). The OCSRI indicates that protection and restoration of salmonid stocks and improvement in water quality are the main roles for state agencies within the Oregon Plan (EO99-01: 1(b)). The Oregon Plan specifies particular actions that state agencies must take to aid in salmon recovery and also directs the Governors Watershed Enhancement Board (GWEB) to help create and organize watershed councils responsible for assessing conditions and determining priorities for watershed health. The Draft Supplement on Steelhead (1997) recommends the use of watershed analysis to provide information that will help refine the understanding of physical and biological processes and how these vary across the landscape. Watershed analysis is intended to serve as an adaptive tool by which watershed councils and agencies will identify environmental concerns and improve overall recovery strategies. The Oregon Plan recognizes the process of watershed assessment as the most useful tool to provide the information basis for management actions and directs GWEB to design a watershed assessment protocol for use by the watershed councils (in 1999 GWEB evolved into the Oregon Watershed Enhancement Board (OWEB)). The resulting assessment protocol is called the Oregon Watershed Assessment Manual (OWAM).

Executive Order 99-01 (EO-99-01) (1999) further clarifies that the State of Oregon will play the leading role in rehabilitating salmonid stocks within the state by continued implementation of the Oregon Plan. It specifies additional methods by which state agencies are to achieve those goals. Part (1), Section (n) directs that agencies use 
geographically referenced data and that they use Geographic Information Systems (GIS) in the analysis of that data. Part (1), Section (0) mandates using geographically based strategies to assess and achieve habitat needs, and that state agencies continue developing standardized watershed assessment protocols.

In the several components of The Oregon Plan the terms 'watershed assessment' and 'watershed analysis' are sometimes used interchangeably. In this paper I consider them as distinct procedures. Watershed assessment characterizes historic and current watershed conditions and identifies broad-scale processes occurring across ownerships within an entire hydrologic basin. The goal of an assessment is to identify major issues and prioritize restoration efforts within the watershed. The OWAM is designed so that watershed councils can perform assessments and meet these goals. Watershed analysis focuses more on a single ownership, landuse, or process and is used to predict watershed responses to various management scenarios. It may include or build upon a watershed assessment.

A watershed analysis protocol is currently being developed by ODF to study the effects of forestry operations on ODF lands. The overall objective is to enable ODF to manage its lands in accordance with mandates and policies, especially those set forth by the State Board of Forestry and The Oregon Plan. ODF has a mandate to be consistent with, but more rigorous than the OWAM when designing its watershed analysis protocol. This will allow ODF to take advantage of the existing assessments performed by watershed councils using the OWAM. 
This project is designed to assist in implementing the ODF watershed analysis process. The specific objectives of the project are to:

- Identify and map all fifth-field watersheds with ODF ownership;

- Determine what data/information ODF needs for each watershed;

- Obtain completed or in-progress assessment work for each watershed;

- Identify or suggest best method of obtaining data;

- Create organization system for information relating to each watershed; and

- Suggest method to prioritize watershed analysis work order.

This paper is separated into sections that correspond to the above project objectives. Section Two discusses how watersheds with ODF ownership are determined. Section Three discusses data assessment and collection. Oregon Department of Forestry's management directives concerning the Oregon Plan and the OWEB protocol serve as the framework to establish data criteria. Section Four describes the database that organizes the data and documents acquired in Section Three. Section Five discusses the methods used to develop prioritization models for ODF watersheds that meet Oregon Plan and ODF management goals. 


\section{IDENTIFYING WATERSHEDS CONTAINING STATE FOREST LANDS}

This section describes the GIS data and procedures used to identify and map all fifth-field watersheds that contain ODF lands. The term 'watershed' refers to an area of land that drains to a common point. In 1987 the United States Geological Survey (USGS) completed mapping of watersheds in the US. The original USGS classification is based on four hierarchical levels where smaller watersheds are nested within larger watersheds. The highest level of watershed identification is the Region (e.g. Pacific

Northwest). Within each Region are multiple Subregions (e.g. Middle Columbia basin). Within Subregions are River Basins (e.g. Willamette River). Within River Basins are nested Subbasins (e.g. Tualatin River)(RIEC 1995). When Subbasins are divided into their constituent hydrologic components we arrive at a fifth-level of watershed division, hence the next lowest level is called the fifth-field watershed, or commonly just 'watershed'.

Identification of fifth-field watersheds containing State forestlands is made using ArcView GIS. Two digital map layers obtained from ODF delineate all fifth-field watersheds located fully or partially within the state. One layer depicts watersheds west of the Cascade crest and is compiled at 1:24,000 scale. The other layer depicts the entire state's watersheds and is compiled at 1:100,000 scale. To maintain the highest amount of accuracy the 1:100,000 scale watershed polygons representing eastside watersheds are merged onto the 1:24,000 scale layer. Another digital map layer obtained from ODF contains polygons representing ODF ownership parcels. The 'select by theme' function is used to find watersheds that intersect with the ODF parcel layer. A total of 132 watersheds are identified as containing ODF lands. 
Some of the watershed boundaries in the digital map layer extend to include the Columbia River and coastal estuaries. Since estuaries do not represent potential ODF lands, this linework is clipped to a map layer representing a more detailed coastline and the Columbia River shoreline. Figure 2.1 outlines the steps to identify fifth-field watersheds with ODF ownership.

The area of each watershed is recalculated for the watershed layer. The intersect function is used with the watershed layer and the ODF parcels layer to combine the watershed name, watershed area, and ODF ownership area into a single database. All ODF parcels are selected from the layer and the dissolve function is used to identify ODF parcels and their total area based on which watershed they occupy. The total ODF land area and the percentage of the basin owned by ODF are calculated for each watershed. The results are tabulated in Appendix A.

Positional accuracy was compared among the ODF parcels layer, Digital Orthophoto Quadrangles (DOQ's), Digital Raster Graphics (scanned 7.5 minute quadrangle maps or DRG's), and the watershed boundary layer. Areas of clearcuts and different-aged timber stands provide a good way of identifying ownership boundaries from the DOQ's. Positional discrepancies among DOQ's, ODF parcels, DRG contour lines, and the fifth-field boundary were as much as 350 feet. Some fifth-field watersheds were identified by the intersect function because a corner of a parcel near a ridgeline slightly overlapped the neighboring watershed polygon. With the known amount of positional error, some of these watersheds could not be positively identified as containing the ODF parcel. Watersheds containing such parcels will be assessed with the watershed to which the majority of the parcel belongs. Seven watersheds are identified this way: 


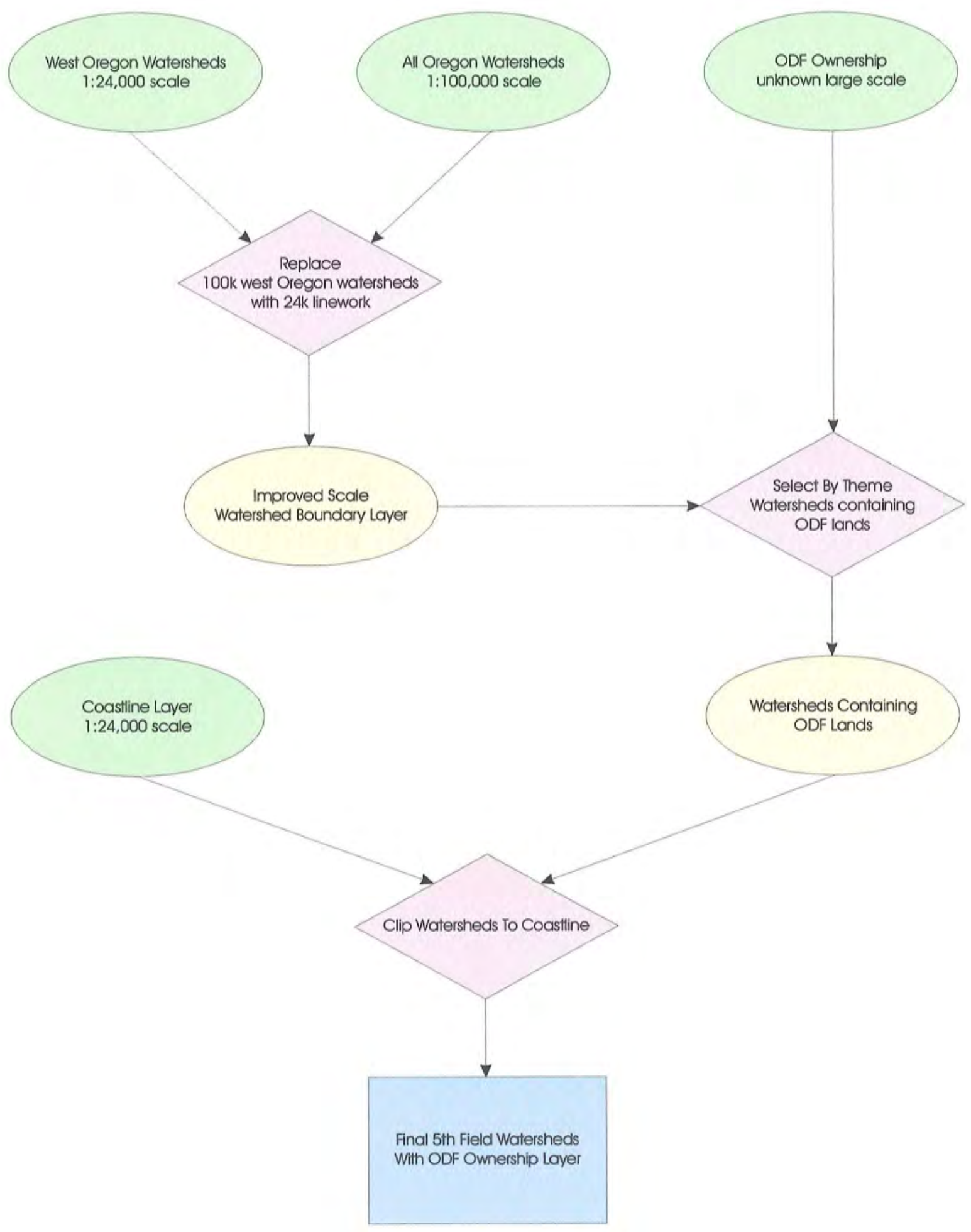

Figure 2.1. Flowchart outlining GIS Analysis steps to identify watersheds with ODF ownership. 
Upper Smith River, Rickreall Creek, Upper North Fork Smith River, Middle Little Deschutes River, Indigo Creek, Pistol River, and Quartzville Creek (see Figure 2.2). It may be necessary to conduct ground surveys to determine if ODF parcels actually exist in these watersheds.

Maps are used to show the location and extent of ODF lands within fifth-field watersheds. Each management district is represented in one of four maps: 1) Astoria, Forest Grove, and Tillamook districts, 2) Coos, Southwest, and Klamath districts, 3) West Oregon and Western Lane districts, and 4) Clackamas-Marion district. These maps are located at ODF offices in Salem. Figure 2.2 illustrates the distribution of ODF lands within associated fifth-field watersheds. Since all ODF lands are located in the western part of the state, the maps in this report show only western Oregon.

Not all of the fifth-field watersheds will be independently analyzed. Watersheds with little state forestland are grouped into larger watershed analysis units (WAU's) based on larger hydrologic associations and ODF district boundaries. The current grouping of fifth-field watersheds into 38 WAU's was done by the ODF watershed analysis work group and in the future will be reviewed by each district and modified if different management needs arise. Figure 2.3 illustrates the current distribution of fifthfield watersheds into WAU's. 


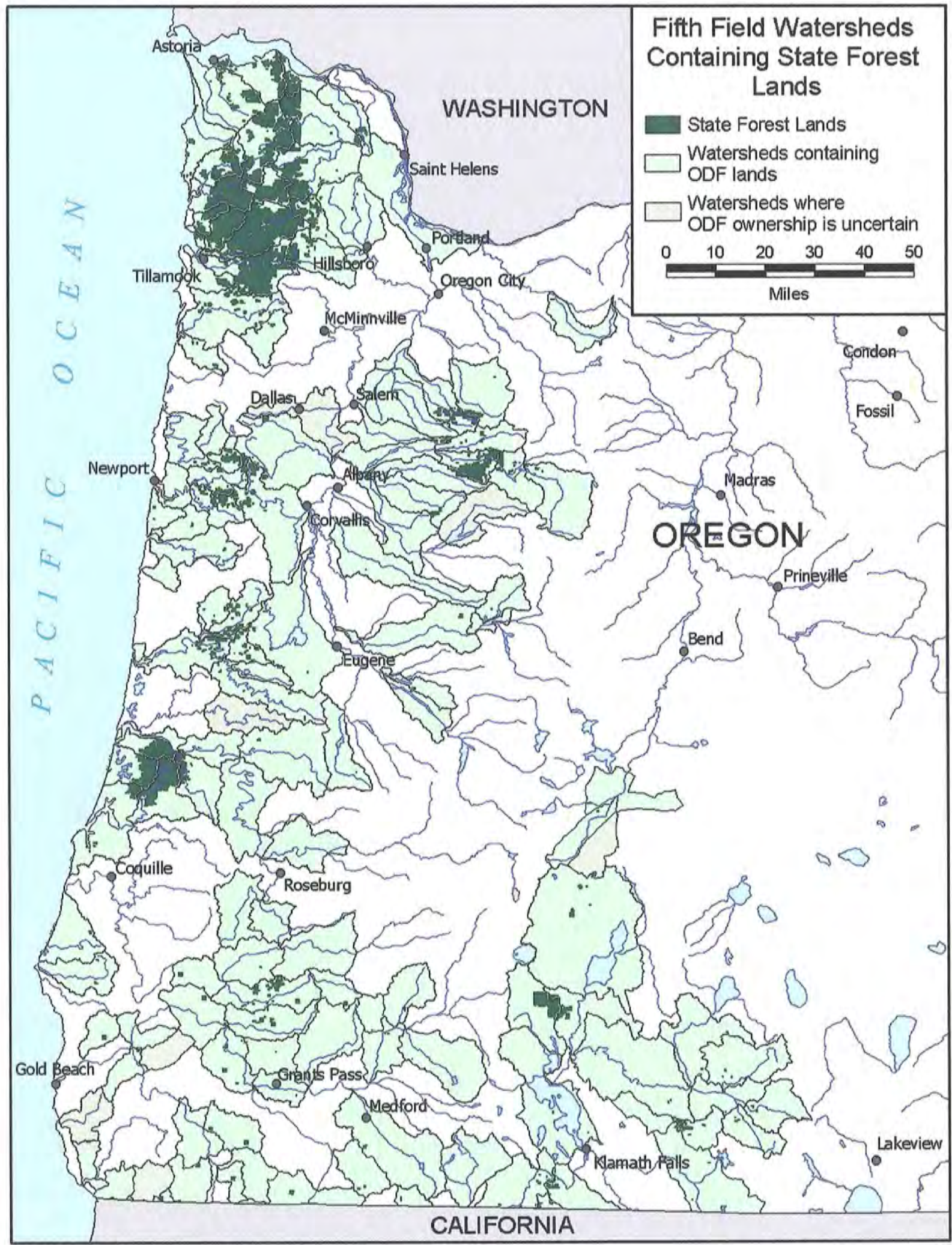

Figure 2.2. GIS analysis indicates there are 132 fifth-field watersheds containing ODF lands. Seven watersheds may be falsely identified because of positional errors in the digital map layers. 


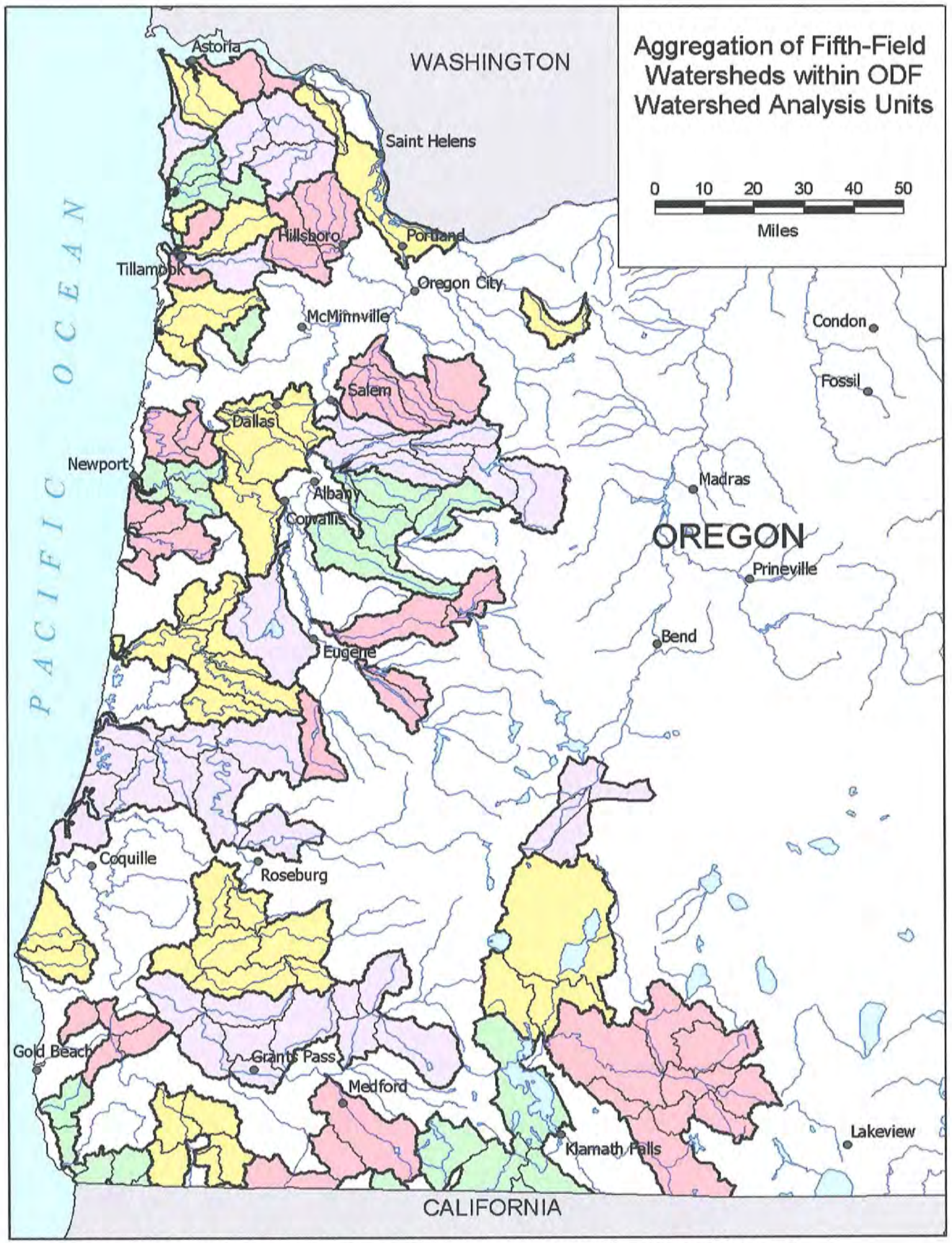

Fig. 2.3. For analytical purposes, 132 fifth-field watersheds are aggregated into 38 ODF Watershed Analysis Units. 


\section{DATA ASSESSMENT \& COLLECTION}

\subsection{Overview}

This section deals with data and information needed to perform watershed assessments and analyses. Several topics are discussed pertaining to data standards, data collection, identifying missing data, and identifying and suggesting other data sources.

Since watershed analysis can incorporate many types of data and information, some standards must be used to assess the applicability of specific data and information to ODF's needs and goals. Since ODF has a mandate to develop a watershed analysis protocol that is consistent with and more rigorous than the OWAM, it serves as a useful baseline to establish data standards. The purpose of the OWAM is to complete a screening-level assessment, using simplified methods to get an initial evaluation of watershed conditions (OWAM VIII-3). The OWAM was designed as a "cookbook" methodology to assist non-professionals in completing meaningful watershed assessments. Within each section certain data sources and/or techniques are recommended (e.g. GIS data layers, paper maps, aerial photographs, gauge records, etc). These sources often state or imply certain information about their scale of compilation, data collection methods, and attributes. Where specific data sources are recommended in the OWAM, I use their attributes as the minimum level of information needed for that information requirement. The issues addressed in the OWAM and the minimum data standards are described in the Data Standards section below. They are also outlined in Appendix B, the table that is used as a decision matrix to assess data applicability.

The OWAM describes assessment techniques to identify issues for different land uses including forest, rangeland, agriculture, and urban. Since there are no urban areas 
within state forestlands I will not spend time assessing data for those areas. I consider rangeland and agriculture data standards only where they may be applicable to forestry operations. For instance, I describe data standards related to soil moisture capacity and erodibility, but not on identifying crop types.

Many watershed assessments have been completed for watersheds containing state forestlands. It is beyond the timeframe of this project to gather or assess all of the data generated from those assessments. However, many of the assessment documents are available and serve as useful sources for existing literature and data that may meet these minimum OWEB standards. The location and organization of these documents is discussed later in the Data Organization section.

\subsection{Data Standards}

The OWAM divides the assessment process into eleven components outlined below:

I. Start-up and Identification of Watershed Issues.

II. Historical Conditions Assessment

III. Channel Habitat Type Classification

IV. Hydrology and Water Use

V. Riparian/Wetlands Assessment

VI. Sediment Sources Assessment

VII. Channel Modification Assessment

VIII. Water Quality Assessment

IX. Fish and Fish Habitat Assessment

X. Watershed Condition Evaluation

XI. Monitoring Plan

The first nine components describe various types of data collection and assessment. This section summarizes the data requirements for each section of the 
OWAM except modules X and XI, which involve evaluating the data and information obtained in the earlier steps and module II, Historical Conditions, as it consists mostly of a list of potential sources of historic information and does not have any specific standards.

Appendix B summarizes the OWAM data requirements outlined below in a tabular format. The table can be used as a matrix to determine data applicability in terms of the OWAM requirements. The column headings found in Appendix B are explained below:

Ch.: Module or Chapter of the OWAM assessment manual.

Item: Corresponds to a key question within the component module.

In some cases there may duplicate records indicating that more than one data source may provide the necessary data. For example Channel Habitat Types (CHT's) in Chapter 3 of the OWAM have three different methods of assessment (see Appendix B).

Data Requirement: Refers to the information needed to answer the key question. Field $(1,2,3 \ldots 8)$ : Description of data that may be useful in identifying potential data sources. The field descriptors might be in the title or key of a map, or a column heading in a table or GIS database.

Scale: If manual specifies scale of data it is noted here.

Blank fields indicate that no further description is specified in the manual. Some data is required for multiple components. Instead of duplicating these items for each component module they occur under the first component number in which they appear in OWAM. For example the Riparian Conditions chapter of OWAM suggests using aerial photos to 
assess vegetation type, tree size, stand density, percent shade, and riparian zone width at a scale of at least 1:12,000. Since data standards for aerial imagery are described in the first section of Appendix B, I do not repeat those standards again in the Riparian Conditions section.

Entries in the Item column that are followed by numbers in parentheses indicate multiple data gathering methods in OWAM. The number refers to the order of preference. Decimal values in the $C h$ column indicate multiple sections within a component of the OWAM manual.

I. Start-Up: The recommended base map is an ODF stream classification map, which is a black and white photocopy of a USGS 7.5 minute topographic maps with stream size and fish presence identified. These maps are compiled at 1:24,000 scale. Sub-watershed delineation is also demonstrated on 1:24,000 topographic maps. Aerial imagery will be necessary for several component analyses. Aerial photos should be at least 1:12,000 scale and preferably color or infrared. Paper orthophotoquads or DOQ's may be used if no aerial photography is available. These standards apply to all following components that rely on aerial imagery. Level III and IV ecoregions existing within the watershed should be identified and described. Land use information is needed that classifies forest, agriculture, rangeland, and urban areas at a scale of 1:24,000 or better.

III. Channel Habitat Types: Channel habitat types are defined by stream gradient, stream confinement, and stream size. The OWAM recommends measuring gradient from topographic contours at 1:24,000 scale. Channel confinement is defined as the ratio of 
bankfull width (approximately the 1.5-year peak flow level) to the width of the modern floodplain (approximately the 100 year floodplain)(OWAM p. III-8).

Designations and possible data attributes of stream size are: Small streams $\leq 2$ cubic feet per second (cfs), Medium streams are between 2 and $10 \mathrm{cfs}$, and large streams $\geq 10 \mathrm{cfs}$ (values are annual averages).

IV. Hydrology and Water Use: This component is divided into a hydrology section and a water use section. The hydrology section is separated into seven steps. Step one data requirements include minimum and maximum elevations, drainage areas, and mean annual precipitation. Precipitation values can be estimated from 1:250,000 base maps. Step three documentation indicates that annual peak flow data from at least ten years is sufficient to establish peak flow characteristics (OWAM p. IV-8). Necessary information includes the year, the peak volume, the date, and the recurrence interval for each year. Step four deals with impacts caused by forestry operations. Data needs include determining which processes cause peak flows in the watershed (e.g. rainstorm events, rain on snow, or spring snowmelt). Other data needs include the historic versus current canopy density. Canopy densities should be derived from 1:12,000 scale aerial photography or ground surveys (OWAM p. IV-10). Step five reviews impacts of agriculture and rangeland. Data needs include hydrologic soil groups and maximum 2year, 24-hour precipitation amounts. Step six assesses impacts of forest and rural roads. Data needs include detailed road layers with information about landslides near roads, road surface condition, and location and number of stream crossings. A less preferable method to identify the location of forest roads is to use aerial photographs. Road 
information should ideally include information on width, ditching, culverts, and surfacing.

The second section of component IV assesses water use. Information is needed about water rights in the watershed. Details include permit/certificate number, status, priority date, flow rate, time of diversion, type of use, location, and the Oregon Water Resources Department's (OWRD) Water Availability Basin (WAB) number. Information is also needed concerning median net water availability per month for each WAB in the watershed and consumptive use as a percentage of $50 \%$ exceedance streamflow.

V. Riparian/Wetlands Assessment: The manual suggests analyzing aerial photos to complete the riparian assessment. Items to note are vegetation type, tree size, stand density, riparian width, and stream shading. Wetland data should be gathered from at least 1:24,000 scale source data. Required data attributes include Cowardin codes, water source, and modification history e.g. diking, ditching, filling, etc.

VI. Sediment Sources: The sediment sources assessment is divided into eight separate source types (roads, slopes, rural roads, urban, cropland, rangeland, burned land, other discrete sources). Each of these source types is further divided into current and potential impacts.

Road condition data needs include road-related landslides, whether the slide reached the stream, slide distance, and the location of the road on the slope. Potential road instability is assessed with data regarding the size of culverts, and 50-year peak flow 
rates. Slope instability (not related to roads) is assessed using information regarding location and depth of landslides, age of nearby vegetation, if the landslide reached the stream, distance traveled, and slope steepness at the initiation point.

There are basic and detailed rural road runoff protocols outlined in the OWAM. The basic protocol relies on color aerial photography interpretation and assesses the total length of roads within 200 feet streams, roads having a slope greater than $50 \%$, road surface, and level of road use. The detailed protocol identifies the percent grade, ditch conditions, cutslope conditions, surface conditions, surface material, culvert conditions, filtering opportunities, and level of road use.

Surface erosion from burned areas requires data concerning soil erosion potential ( $\mathrm{K}$ value), slope steepness, and burn intensity. Ground observations are needed to assess the conditions of access roads and fire lines and the severity of erosion. Future plans for timber harvest, road building, or burning that may increase sedimentation should also be noted in this section.

VII. Channel Modifications: Channel modification assessment has few specific data requirements. Table 1 (OWAM p. VII-7) lists potential channel modifications such as dams, reservoirs, fire ponds, culverts, fill associated with road building, historic splash damming, and stream clearing. The location of the 100-year floodplain should also be delineated. Data should be acquired or plotted at 1:24,000 scale or better.

VIII. Water Quality: The water quality assessment component is based on EPA and ODEQ guidelines. The data collection segment involves two steps from which relevant 
data standards can be inferred. The first step requires identification of sensitive beneficial uses and water bodies on the 303(d) list. The next step is to identify water quality criteria applicable to the Sensitive Beneficial Uses, defined by ODEQ, in each basin. Criteria relevant to fish species include temperature, dissolved oxygen, $\mathrm{pH}$, nutrient levels, bacteria, chemical contaminants, and turbidity (OWAM p. VIII-9). Additional data needs include ODEQ's 303(d) listing decision matrix and Outstanding Resource Waters status of water bodies in the watershed.

IX. Fish and Fish Habitat: The fish habitat assessment component of OWAM divides data needs into three main groups. The first group examines fish species and populations. It requires data concerning current species presence, threatened or endangered status, extinct species, stocking history, and life history pattern and locations of current species. The second group summarizes habitat conditions. It requires data concerning pool habitat conditions, riffle and woody debris conditions, and riparian habitat conditions. Ground verification is recommended using the ODFW survey protocol. The third group identifies migration barriers. Data needs include culvert and stream dimensions near culvert inlets and outlets.

\subsection{Data Identification \& Collection}

This section identifies specific data and information that meets the standards of the OWAM methodology. In accordance with EO-99-01 georeferenced or digital data takes precedence over paper or tabular data formats. The specific agencies, persons, Internet links, or other contact information for each data item is stored in the watershed 
database and is discussed in the Data Organization section. The organization of this section follows the same OWAM component module outline as in the previous section.

I. Start-Up: USGS has scanned 7.5-minute 1:24,000 scale quadrangle maps available as Digital Raster Graphics (DRG's). The Regional Ecosystem Office has released a GIS data layer representing nested $1^{\text {st }}$ through $6^{\text {th }}$ field watersheds. This coverage eliminates the need to manually delineate sub-watersheds and ensures uniformity between watershed basins. An ecoregion shapefile is available from the Oregon Geospatial Data Clearinghouse (OGDC). This data can be used to estimate the percentage of ecoregions within watersheds. The corresponding Ecoregion Descriptions Appendix file contains the level III and IV ecoregion descriptions. OGDC also has a shapefile representing zoning that can be used as the base data on which to refine landuse descriptions, however, it is compiled at a smaller scale than the recommended 1:24,000.

Aerial imagery in the form of digital orthophotos and stereo pairs are available for ODF lands. Color, 1-meter resolution digital orthophotos from Summer 1995/1996 are available for most ODF districts except portions of the Western Lane district. Astoria has acquired 2001 color orthophotos from Clatsop county. Tillamook and Grants Pass are in the process of acquiring 2000/2001 black and white 1-meter orthophotos from BLM. Color orthos should be acquired during the summer of 2003 for Forest Grove, Clackamas-Marion, West Oregon, Western Lane, Klamath, and Coos districts. Color and black/white stereo pairs are available for various years and scales at district offices. 
III. Channel Habitat Types: Topographic contour lines from DRG's meet OWAM standards for measuring stream gradient. ODFW distributes georeferenced habitat surveys that provide information on channel slope, channel confinement, valley floor types, channel form, and adjacent landforms. These surveys are compiled from many different sources from different times and do not exist for all streams. The OWAM cautions that some of these surveyed stream reaches are inconsistently defined.

IV. Hydrology and Water Use: Digital Elevation Models (DEM's) compiled at 1:24,000 scale can be used to derive maximum and minimum elevations. Suitably accurate drainage areas are attributed within the watershed shapefiles created by the Regional Ecosystem Offices.

The OWAM suggests three possible sources to acquire mean annual precipitation data. Two of the three sources sell $2-\mathrm{km}$ resolution grids representing values developed from $1: 250,000$ base maps. The OGDC has a precipitation shapefile representing precipitation isolines, but it does not include metadata. Another possible source is a 1:250,000 scale digital graphic available at the NOAA image document library website.

Peak flow data is available from the USGS water resources website. Necessary information includes the year, the peak volume, the date, and the recurrence interval for each year. The data is taken from USGS gauges and does not exist for all watersheds. Greenberg and Welch (1998) have also compiled some peak flow series in western Oregon. The previously mentioned ecoregion appendix contains descriptions of peak flow processes (i.e. rainstorm events, rain on snow, or spring snowmelt) and estimated historic canopy densities. 
Hydrologic soil groups mapped at 1:24,000 scale are available from georeferenced NRCS soil surveys (http://www.or.nrcs.usda.gov/pnw_soil/mo1_gis.html). These soil surveys do not cover all areas of the state so older soil maps or further research may be necessary for those areas. Desert Research Institute hosts a digital image map that can be used to find 2-year, 24-hour maximum precipitation values. The length of forest and rural roads can be calculated from district road shapefiles available at ODF. Surface and groundwater water rights can be summarized using the online Water Rights Information System (WRIS) and mapped using GIS vector files available from OWRD. Water availability at the $50 \%$ exceedance level for each month can be summarized using the Water Availability Reports System (WARS), also available from OWRD. Watersheds designated as streamflow restoration priorities by OWRD and ODFW can be identified from 1:24,000 shapefiles provided by those agencies.

V. Riparian/Wetlands Assessment: Locations and Cowardin classifications of wetlands can be obtained from National Wetland Inventory digital map layers at 1:24,000 scale, however, data does not exist for every location in the state. Detailed local wetland surveys are available from many municipalities in the state and the Division of State Lands, however none were acquired and assessed during the timeframe of this project.

The best place to obtain riparian condition data that meet OWAM standards is from watershed councils or consulting firms that have completed an OWEB Assessment. This should be done at the beginning of a watershed analysis because of long lead times on the part of watershed councils and contractors to locate and distribute the data. 
VI. Sediment Sources: The ODF Road Hazard Inventory is designed to identify inputs of sediment from forest roads due to construction, surface erosion, and landslides. The inventory identifies three sources of road hazards: Spacing and location of cross drainage structures, length and discharge of ditches, and sidecast road fill on steep slopes.

ODF has completed the Road Hazard Inventory for each district. The Road Inventory Survey (RIS) database has been linked to existing GIS road layers for Tillamook, Clackamas-Marion, West Oregon, Western Lane, and Klamath districts. These districts are able to maintain and update their road activities directly into the RIS database via a graphic interface, and should have the latest ODF road hazard inventory. Coos district has point shapefiles generated from GPS readings during the survey, but no operating database interface. Astoria, Forest Grove, and Grants Pass districts have original survey data in varied formats.

Some indicators for potential and actual road instability can be derived from RIS by querying the sidecast and surface condition tables. The tables contain data concerning slope steepness, road movement, vegetation development, fill depth, width, condition, slope location of the road, potential for slides to reach stream, road surface condition, and some culvert dimensions. It lacks information on existing road failure such as landslide type, distance, and whether it reached the stream.

Forest/rural road runoff can also be estimated using data from RIS. Useful data items include location of drainage features, ditch conditions, surface conditions, surface material, culvert condition, filtering opportunities, and road use. Relevant information not included in RIS is road grade and cut-slope condition. 
Potential slope instability can be taken from ODF debris flow hazard maps. Fiftyyear peak flow rates are also available as GIS data layers from ODF. Soil erosion potential data is available from the NRCS SSURGO data layers for most portions of the state.

VII. Channel Modifications: The 100-year floodplain can be acquired at a suitable scale from FEMA Q3 GIS layers. The Oregon DEQ website maintains tabular and GIS data layers that meet OWAM standards relating to water quality standards, issues, beneficial uses, and 303(d) listing status and parameters. Some channel modifications such as dams, reservoirs, and fire ponds can be found on 1:24,000 scale DRG's.

VIII. Water Quality: The Oregon DEQ website maintains several tables and data layers that address OWAM water quality criteria. Beneficial uses are identified in basin tables, as are lakes and streams on the 303(d) list. The Oregon Water Quality Standards document identifies water quality criteria related to the existing designated beneficial uses. Also within the water resources section of the DEQ website are the 303(d) listing decision matrix and a list of Outstanding Resource Waters.

Further studies and information relating to particular water quality variables are available from USGS offices and the USGS online digital library. Many of these studies may be useful for watershed analyses since they identify and contain extensive studies of existing watershed related problems. All identified documents that apply to ODF watersheds are catalogued in the watershed database described in Section 4. 
IX. Fish and Fish Habitat: The OWAM recommends the ODFW basin plans as sources for tish population information. Copies of these reports should be obtained from ODFW offices. Habitat surveys completed by ODFW meet the OWAM requirements to complete the habitat condition summary. These files contain robust information, but data gathering is not completed for all streams. These files may serve as a tool to aid in identifying channel habitat types and riparian conditions as well. The OWAM posts a warning about inconsistent sampling with these datasets so field sampling may be necessary to confirm the data and fill in gaps in unsurveyed streams.

\subsection{Data Gaps}

There are several key pieces of information outlined in the OWEB methodology that are not readily available and will need to be gathered before or created during each watershed analysis. Some of this information exists, but the data resides in many different locations and collection time exceeds the scope of this project. Since the information needs are based on the OWAM protocol, watersheds that have completed an OWEB sponsored assessment should possess some type of information relating to these gaps. Since the exact data is not located and cannot be assessed as to the accuracy or compliance to the OWAM protocol, they are treated as 'gaps' in this section. Information about channel habitat types is necessary to analyze hydrologic impacts and habitat suitability. Many existing watershed assessments and analyses have performed some type of channel habitat type analysis, however, the data is not in one central location and will need to be gathered from the relevant agency, watershed council, 
or contractor that gathered or maintains the data. Channel confinement data will likely need to be developed for areas without previous watershed assessments.

Detailed information is not widely available for current forest canopy density. The stand level inventory currently being conducted by ODF is likely the best source for an estimate of canopy density for state forestlands.

Some measure of riparian conditions has been studied during most OWEB watershed assessments. The data has been gathered under different methodologies and must be obtained from various watershed councils, agencies, and/or contractors.

Although ODF does have a recent inventory of landslides, certain data was not collected in the methodology. To meet the OWEB standards landslide depth, age of vegetation cover, and stream impact should be noted.

Data is lacking on the effects of forest fires on watershed health. Relevant information should contain information on the amount of burned area, the erosion severity, and the condition of access roads and fire lines. ODF maintains some GIS layers showing the extent of recent fires, but these do not include any severity attributes.

There is no wide-scale source for identifying historic channel modifications. Several items will need to be researched on a watershed-by-watershed basis. These include fill and structure permits from USACE or ODSL, and bank stabilization/ channelization projects. There are few precise standards for this kind of data, so historic records or current observations may be necessary to provide needed information.

Water quality measurements are available for a limited number of sites or are located in many different locations. New measurements or additional measurements may be needed within watersheds lacking in sufficient water quality monitoring. 
The largest gaps regarding fish habitat concerns culvert dimensions and fish passage ability. The location of culverts is well documented in several data sources but most are not attributed with dimensions or fish passage ability information. The Forest Practices Division has performed some detailed culvert analyses, but these are mostly on private lands.

\subsection{Other Data}

There are several data sources that do not meet any OWAM criteria but may be useful in the ODF watershed analysis effort. The data is available at ODF and pertains to ODF lands. Following is a brief description of these datasets.

Forest disease/pathogens: The Forest Health section of the Forestry Assistance division of ODF performs annual tree mortality surveys using airborne mapping techniques. The surveys are sketch mapped onto 1:100,000 scale USGS quad sheets and attributed with the agent and intensity of disturbance. Possible agents include over 60 types of insect, 14 types of diseases, and 6 types of physical damage. Most damage is attributed to Douglas fir bark beetle, bear damage, and pine beetle. The survey is flown over all forested lands in Oregon and Washington each year. The resulting sketch maps are digitized and compiled into region wide GIS coverages for each year from 1980 to present. A ground verification report of the 2000 survey indicates that half of the aerial survey polygons are within 0.2 miles of the true location and all polygons are within 0.75 miles of the true location.

An airborne survey of Swiss Needle Cast extent has been flown annually since 1996. It covers the area from the Columbia River south to Bandon and inland 20 miles 
from the coast. Four GIS coverages are available for years 1996-1999, 2000, 2001, and 2002. Mapping techniques are similar to the statewide mortality survey, so the high level of accuracy should be similar.

Ground surveys of root diseases are done for areas requested by district personnel. The surveys are available as hardcopy maps and digital images from the districts or from forestry assistance. These surveys are potentially useful to the ODF watershed analysis effort because much of the next decade's timber management planning as outlined in district implementation plans pertains to treating infected stands; especially Swiss Needle Cast in the northwest portion of the state, and beetle infestation in southern and eastern forest lands.

Watershed Restoration Database: A program called the Oregon Watershed Restoration Inventory collects reports by state agencies, large landowners, and other involved parties on watershed restoration activities. The database catalogs the landowner, type of restoration, location, and many other attributes. These databases can be dynamically segmented onto $1: 100,000$ stream lines to perform spatial analysis in a GIS. The inventory serves as a potential source to analyze the results of past restoration efforts as well as areas with lack of restoration efforts.

State Forest Management Shapefiles: Several GIS layers pertain to ODF management districts that are potentially useful in analyzing processes on state forestlands. The GIS layers show the positions of road gates, forest management classifications, management basins, timber sales, and historic seed sources.

OWEB has begun to investigate the feasibility of creating a watershed assessment summary database to organize important information and data reported in watershed 
assessments. I recommend that ODF design a similar summary for its future watershed analyses in order to quickly find and compare data from different watershed studies. This would also assist scientists, researchers, and the general public in finding and comparing changes in watershed conditions over time. 


\section{DATA ORGANIZATION}

This section discusses the concept and design of the Watershed Information Database. After data and documents have been identified, collected, and assessed, they need to be organized so that they can be found and used when needed. A relational database is a useful way to organize over 200 documents and 65 data items that cover different areas at different scales in different formats. Using user interface forms in a digital database also allows easy entering and editing functions to change the database as new documents and data are found.

The basic framework of the database identifies information as having two components, type and extent. The type differentiates items as either a document or a data record. Information fields relating to documents are the title, author, publication date, format, location, and a hyperlink field, if online. Data items are stored with information about their title, filename (if digital), originator, scale, location, hyperlink field, if online, abstract description, and a purpose description. The extent refers to what geographic area the information covers. Most of the data and documents gathered relate to specific watersheds, state forest management districts, or cover the whole state/region. In order to logically organize these different extents, information is either identified with a specific watershed or with a specific ODF district (data or documents that are statewide in scope are arbitrarily assigned to the district category).

The database stores information in four different tables: Watershed Data, Watershed Documents, District/State Data, and District/State Documents. There is a form for each of these tables where data can be searched, edited, or entered. There is also a main reporting form, where all of the data and documents related to a specific WAU 
can be generated as a list. These lists can be used to let contractors know what information is available and allows ODF to quickly locate and compile needed information. Appendix C is the Watershed Database Users Manual, which explains in more detail how specific tables are linked and queried, and outlines step-by-step instructions how to perform querying and reporting functions. 


\section{WATERSHED PRIORITIZATION}

\subsection{Overview}

This section describes the goals and foundations for designing a model to prioritize watershed analysis. The model seeks to prioritize watersheds in terms of ODF operational and management needs in accordance with the goals of the State Board of Forestry and the Oregon Plan for Salmon and Watersheds. The goal of the prioritization model is not to perform highly detailed assessments of each watershed but rather to analyze statewide and/or broad-scale data to identify potential risks and address ODF management goals. The model is also designed to be able to incorporate new issues and concerns as they are identified. The model attempts to meet the goals of the OPSW and ODF by prioritizing watersheds that: 1) have the highest potential risks to salmon habitat and water quality associated with forestry operations, 2) have the highest degree of ODF activity, and 3) watersheds that have been previously prioritized by other state agencies or that contain high profile resource or contractual issues (e.g. municipal watersheds). The prioritization process is in accordance with EO-99-01 in that it employs a GIS to analyze spatially referenced data and uses geographically based strategies to assess broad-scale habitat needs and risks.

Three hierarchical screens are used to assess these criteria for each watershed. The first screen uses a GIS to quantify overall watershed conditions in terms of actual or potential risks to anadromous fish species related to forestry operations. The second screen factors in the relative influence of ODF operations in the watershed in terms of percent ownership in a watershed. The third screen weights watershed scores by considering qualitative resource concerns such as presence of ODFW streamflow 
restoration basins, salmon anchor habitat, and municipal watersheds. Each screen modifies the priority score of the screen before it. The $1^{\text {st }}$ screen priority score is modified by the $2^{\text {nd }}$ screen, and the $2^{\text {nd }}$ screen priority score is modified by the $3^{\text {rd }}$ screen. The results of the $3^{\text {rd }}$ screen represent the final priority score.

The prioritization method attempts to do three things. First, it provides two methods of analyzing watershed priority. The first method analyzes the overall magnitude of priority issues within each watershed. The second analyzes the density of priority issues so that the overall size of a watershed does not affect its ranking relative to a smaller watershed.

Each model has advantages for watershed management. By prioritizing watersheds with the highest total number of issues, watersheds with large areas will tend to be promoted first, so that the most ODF acreage will be analyzed in the shortest period of time. On the other hand, prioritizing watersheds with the highest density of issues ensures that each dollar per acre of watershed analysis addresses the most issues at once.

The second goal of the prioritization method is to weight attribute scores equally so that one factor or condition within a screen does not count more than another. (This can be modified to emphasize certain factors if needed).

Thirdly, the prioritization method normalizes scores so that criteria such as distances and acreage can be compared to each other. Normalizing scores also allows easier classification of scores so that priority rankings can be viewed as integers within a simple scale. 


\subsection{Screen One}

\subsubsection{Description}

The first screen establishes a base score for each watershed that represents the overall potential risk to anadromous fish species. The parameters chosen to represent potential risk come from the OWAM's list of potential forest management effects upon stream conditions. This screen uses GIS data gathered at similar scales and using similar collection methodologies to compare conditions between watersheds.

The Watershed Fundamentals section of the OWAM (p.38) identifies several potential disturbances and potential watershed responses associated with timber harvest. Removal of the riparian canopy can lead to increased summer water temperatures and reduced woody debris recruitment to the stream. Soil disturbance and improperly created/maintained roads can lead to increased runoff of sediment, reducing the quality of salmon spawning and rearing habitat. Alterations of vegetation cover can alter the timing and magnitude of peak flows as well as the timing and characteristics of landslides.

Eight statewide digital map layers are used to represent data concerning the issues mentioned above. The data layers represent threatened and endangered fish species habitat, road density, debris flow hazards, and stream water quality. The data layers and the information they provide are outlined below.

The Oregon DEQ is responsible for listing portions of water bodies that do not meet certain water quality criteria identified in the Clean Water Act (known as the 303d list). They distribute GIS data that links failed criteria to stream reach files. A measure of water quality risk potentially due to forestry operations can be estimated from the length of streams failing standards for temperature, sediment, or fish habitat. 
Potential risks associated with forest road runoff can be estimated from digital map road layer. Each ODF district maintains a roads layer for roads within state forestlands. Determining the density of forest roads within each watershed can serve as an estimate of road-related runoff potential. The data is not detailed enough to assess the quality of roads so the accuracy of the analysis may vary based on different road conditions between districts and watersheds.

Data from ODF debris flow hazard digital map layers allow a measure of slope instability and potential sedimentation risks. The data is derived from slope, stream channel confinement estimates, soil type, debris flow locations from the ODF 1996 study and other historical accounts.

A measure of risk to specific fish species can be estimated from data created by ODFW. The fish distribution data is used to identify stream habitat in ODF related watersheds containing threatened or endangered fish species. The extent of a species use of the stream is based on the observations and best professional judgment of ODFW staff biologists and the professional observations and opinions of staff from other natural resource agencies.

To compare the different magnitude and density values of varying characteristics like water quality, road density, and length of stream habitat the data must be normalized to some common scale. The magnitude and density value for each characteristic is normalized using a linear transformation. All values are standardized to a value $(\mathrm{N})$ between 0 and 100 using the formula:

$$
\mathrm{N}=(\text { watershed value }- \text { minimum value }) /(\text { maximum value - minimum value }) \times 100
$$


This formula ensures that the highest value in each category will get a score of 100 and the lowest value will get a score of 0 . By chance, all characteristics measured in this screen contain at least one minimum value of zero, so the score for each watershed characteristic is in effect the percentage of the maximum value. For example, hypothetical Watershed A has the most miles of endangered fish habitat at 75 miles. Watershed B has 25 miles (one-third of 75) of endangered fish habitat, and Watershed C has 0 miles of endangered fish habitat. Following the equation for $\mathrm{N}$ from above, Watershed A will receive a score of 100 , Watershed $C$ receives a score of 0 , and Watershed B receives a score of 33.33, or one-third of the maximum value (Watershed A).

Data quality varies or data may be non-existent in some areas, which affects the final scoring. Some ODF districts have invested in detailed road network GIS layers, which may imply a greater forest road density. This probably does not skew the measure inordinately since the districts investing in detailed roads layers are the districts containing the largest ODF acreage, so the investment in detailed roads layer reflects the higher level of management activities, which include higher road densities. Counties on the east side of the Cascades do not have debris flow hazard maps in GIS format. This is partly due to the fact that eastside areas receive considerably less average precipitation, and therefore are not as susceptible to debris flows. The lack of data for eastern counties probably does not influence the overall priority rating significantly since most ODF lands east of the Cascades is located on relatively flat terrain. 
The estimates of fish distribution may reflect some degree of interest in researching specific areas as opposed to purely random sampling from across the whole state, in which case the estimates of fish distribution may be somewhat skewed.

Given these possible biases, the scoring method may suggest that there are fewer potential risks in areas with lower quality or missing data. The potential errors in $1^{\text {st }}$ screen scoring are accounted for in the $2^{\text {nd }}$ screen where watershed scores are highly modified by percent ownership and priority rankings are grouped into classes. The effects of the $2^{\text {nd }}$ screen scoring far outweighs data discrepancies in the first screen and grouping priority scores into classes insures that a watershed ranked only slightly lower due to missing data will still remain in a class comparable to similar watersheds.

\subsubsection{Techniques}

The base layer used in all of the following analyses is the fifth-field watershed layer available from ODF. The data follows the USGS hydrologic boundary and naming convention as of 2001 .

The ODFW fish distribution data is represented as 1:100,000 scale stream lines attributed with Federal Endangered Species Act and Oregon Sensitive Species List designations. Multiple shapefiles contain data for Spring Chinook, Fall Chinook, Summer Steelhead, Winter Steelhead, Coho, and Chum salmon habitat.

The data is intersected with the ODF watershed layer to attribute stream habitat to specific watersheds. The GIS layer is queried to identify streams containing species with federal designations of: proposed threatened, listed threatened, candidate, proposed endangered, or listed endangered as well as state designations of: endangered, threatened, 
critical, or vulnerable. Since the goal of this prioritization screen is to assess potential risk to salmon populations in each watershed, habitat with an ESA listings of 'proposed threatened or endangered' are analyzed along with known listed species. Since a proposed ESA listing involves some concerns and evidence regarding declining populations, it is a useful indicator of potential risk. The resulting data is summarized by watershed to determine the total length (in feet) of habitat for each species. The process is repeated for the six species and the data joined to the digital map layer named screen 1 (see Figure 5.1).

The length of stream habitat for all six sensitive species is added together in the FishTotLen field. The density of sensitive fish habitat is calculated as the total length of all sensitive species habitat divided by the area of the watershed that lies within Oregon (all of the data used in this screen represent land in Oregon only; watersheds that are partially located in California are clipped at the state line and treated as small fifth-field watersheds). The total habitat distance is normalized and placed in the FshLenIndx field. The fish habitat density value is normalized and placed in the FshDnsIndx field.

Potential water quality issues associated with forestry operations are assessed using Oregon Department of Environmental Quality data. The coverages are represented as the same 1:100,000 scale stream lines as the fish data, but attributed with failed criteria measurements taken from the 1998 303(d) water quality impairment list published by DEQ. Streams are selected if they do not meet the criteria for temperature, sedimentation, turbidity (as a surrogate where sedimentation was not directly measured), and habitat modifications. The total length of the selected streams is placed in the field 


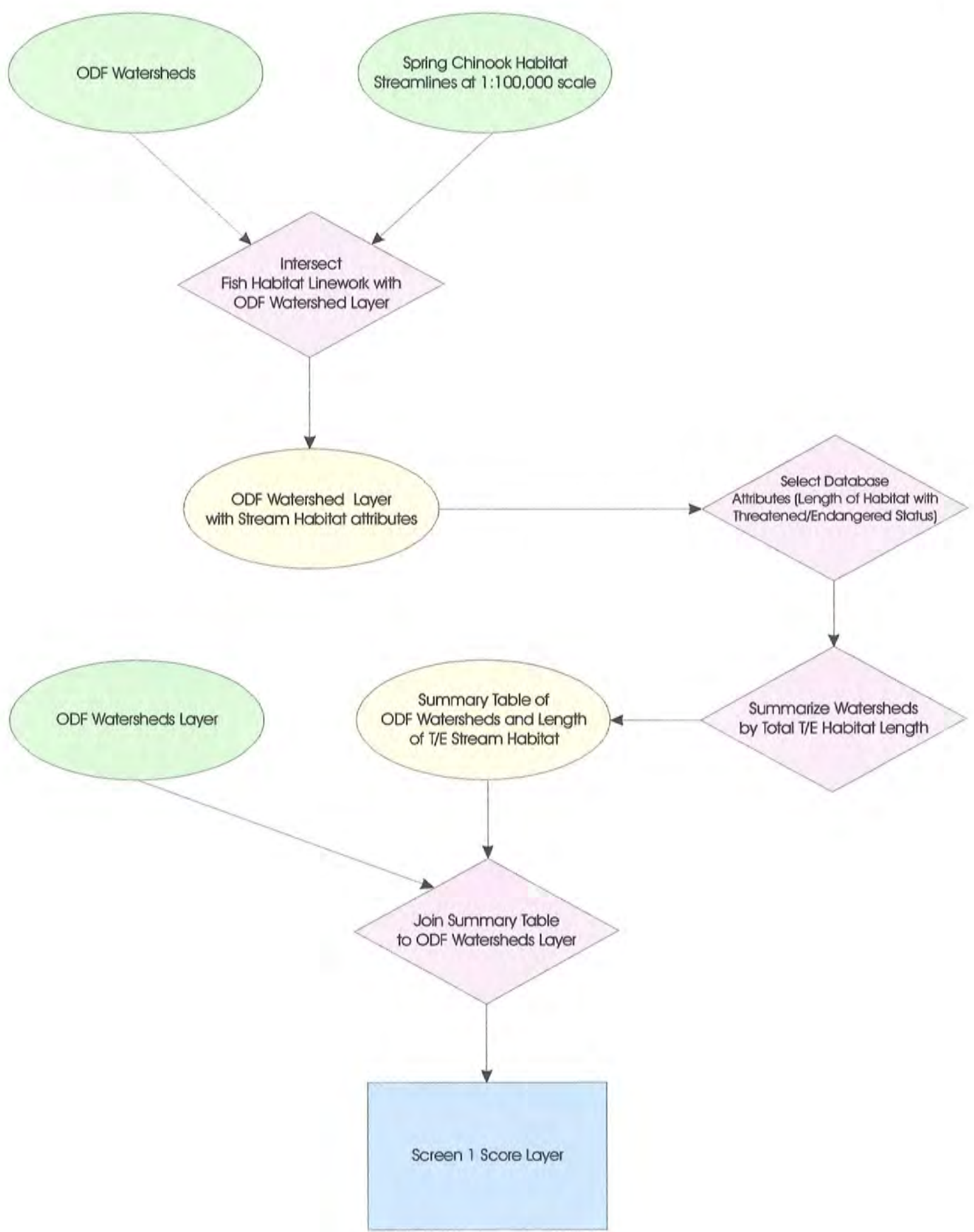

Figure 5.1. Flowchart of GIS Analysis to determine $1^{\text {st }}$ Screen watershed priority score. These steps are repeated for each data layer used in the $1^{\text {st }}$ screen. Each data layer adds its summarized score to the Screen 1 GIS layer. 
named 303dLength. The total length is divided by the in-state watershed area to determine the density and these values are placed in the field named 303dDens. Both fields are normalized and the new values placed in the 303lendex and 303dendex fields respectively.

The ODF debris flow hazard shapefiles contain data for western Oregon counties derived from 30 meter DEM's, stream channel confinement estimates from DRG's, susceptible soil types, debris flow locations from the ODF 1996 study and other historical accounts. Polygons are attributed with descriptors of moderate, high, or extremely high risk of debris flow. An intersect function is used to calculate the area of high and extremely high-risk areas within each watershed in the DebrHaz field. A density value is obtained by dividing the risk acreage by the in-state watershed acreage and placed in the DHDensIndx field. No data was available for eastside counties so they receive default values of 0 . The overall debris flow hazard acreage and the density acreage are both normalized and the new values placed in the DhazIndx and DHDensIndx fields respectively.

The road density on ODF lands in each watershed is estimated in order to account for potential risks such as road failure and sedimentation from runoff. The most accurate road layers are merged from each of the districts. The roads are then intersected with ODF lands and the resulting road distance divided by the total ODF acreage for each watershed. This results in a road density value of miles per acre. The density score is normalized and placed in the field Roadindex. Only one index score is created for roads since the data layer only includes roads on or near ODF parcels. An index based on the 
total length of roads would measure ODF percent ownership more than an index of road length in each basin.

Final watershed scores are then calculated for the first screen. The first score (Scorlmag) is based on the magnitude of risk factors and is calculated by summing the normalized scores of the total sensitive fish habitat, total water quality limited distance, total debris flow hazard acreage, and a value of 1 to eliminate potential null values. The second score (Scor1dens) is based on the density of risk factors and is calculated by summing the normalized density values for fish habitat, stream quality, debris flow hazard, road density and, a value of 1 to eliminate null values.

Scores based on magnitude range from 1 to 222 with a mean of 54 and a standard deviation of 42 . Scores based on density range from 1 to 230 with a mean of 90 and a standard deviation of 47. The top two maps in Figure 5.2 use choropleth maps to illustrate the spatial distribution of scores. The magnitude scores tend to prioritize larger watersheds while density scores allow smaller watersheds to take priority. The bottom map in Figure 5.2 illustrates the difference between the magnitude and density scores. 


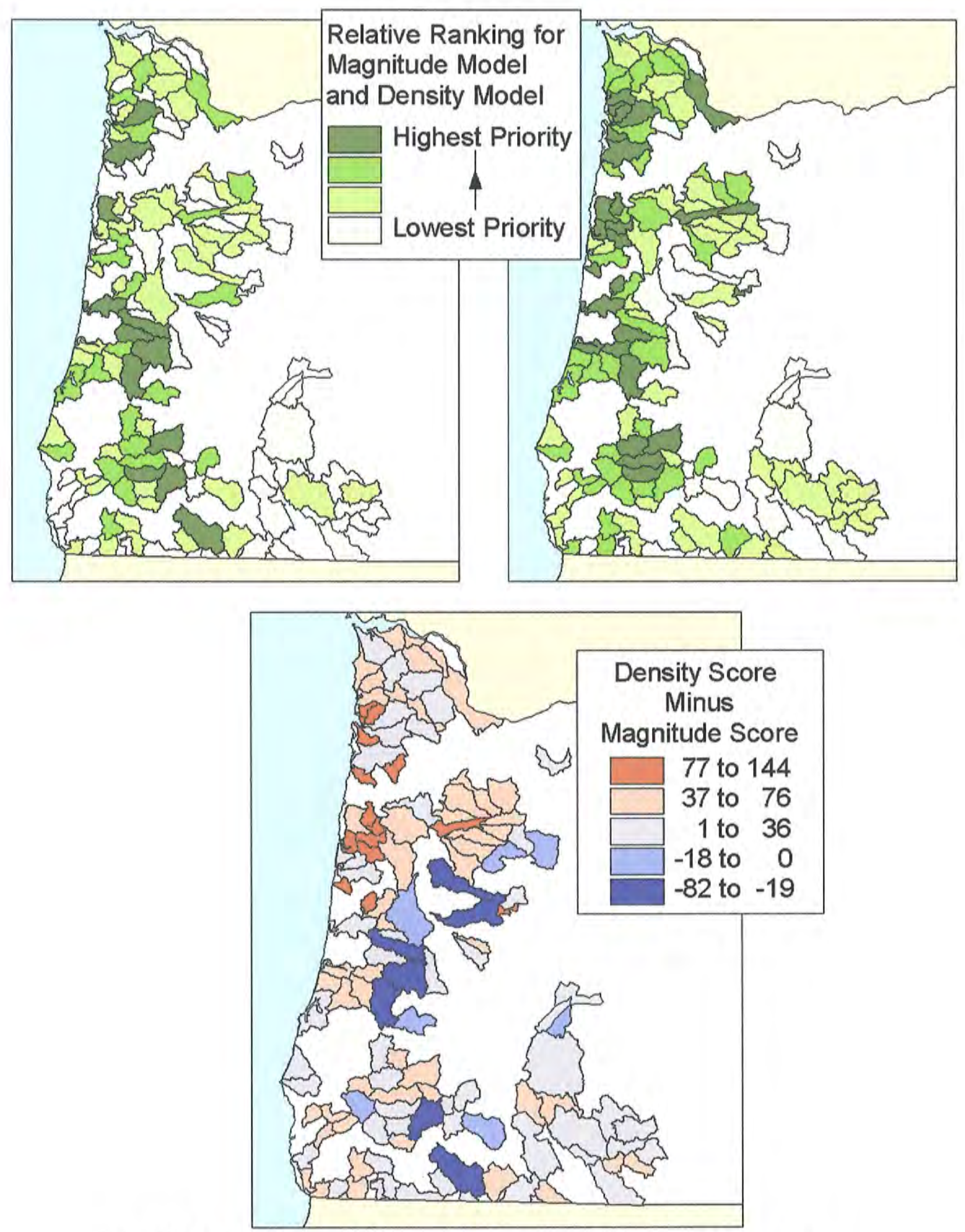

Figure 5.2. Spatial distribution of $1^{\text {st }}$ screen priority scores Magnitude methodology is shown on left above, Density methodology is shown on right above. Lower map shows difference between Density Model and Magnitude Model. 


\subsection{Screen Two}

\subsubsection{Description}

The second screening process assesses the potential influence of ODF management activities in each watershed. The score is based on the percent of ODF ownership within each watershed. The goal of the second screen is to ensure that the priority rating from screen one is moderated by the overall influence of ODF operations in the watershed. Watershed scores are then grouped and assigned an integer value on which screen three scores are based.

\subsubsection{Techniques}

To determine the percent of ODF ownership within each watershed, the watershed digital map layer is intersected with the ODF parcels layer. The intersected ODF parcels are then dissolved based on their new fifth-field watershed name attribute. The total ODF land area is calculated for parcels within each watershed and divided by the total size of the watershed.

The magnitude and density scores from the first screen are multiplied by the percent ODF ownership. The resulting score models the overall potential influence of ODF forest management activities in each watershed. The screen two index scores are then grouped into priority classes.

The Jenks Optimization formula is useful for grouping multimodal or heavily skewed distributions like those that commonly result from geographic distributions. The Jenks classification formula seeks to minimize the variation within each class of data while maximizing the variation between classes. The result is that data is classified along 
'breaks' where there are large jumps in value (Jenks 1967). ArcView employs the Jenks Optimization algorithm using a classification tool called Natural Breaks. To run the algorithm, the user must choose the number of classes into which the data will be grouped.

The screen two scores are classified into four groups. Four was chosen for several reasons. The histogram in figure 5.3 suggests that there are four main modes in the distribution of screen two scores. Having four classes also ensures that watersheds with the lowest screen two ranking cannot become the highest priority in the next screen (discussed later). By limiting the number of classes to four, the potential inaccuracies due to missing or faulty data in the first screen datasets can be minimized, since all watersheds with similar scores will be rounded up or down into one of only four classes.

After the data has been classified into groups, an integer value ranging from one to four is assigned each watershed. The watersheds grouped into the highest classification receive a score of 4 and the watersheds in the lowest classification receive a score of 1 . Figure 5.3 illustrates the distribution of screen two density scores and their corresponding integer classifications. The magnitude score follows the same basic distribution pattern. The overall spatial distribution closely follows the patterns of ODF ownership. Figure 5.4 illustrates the spatial distribution of screen two scores. 


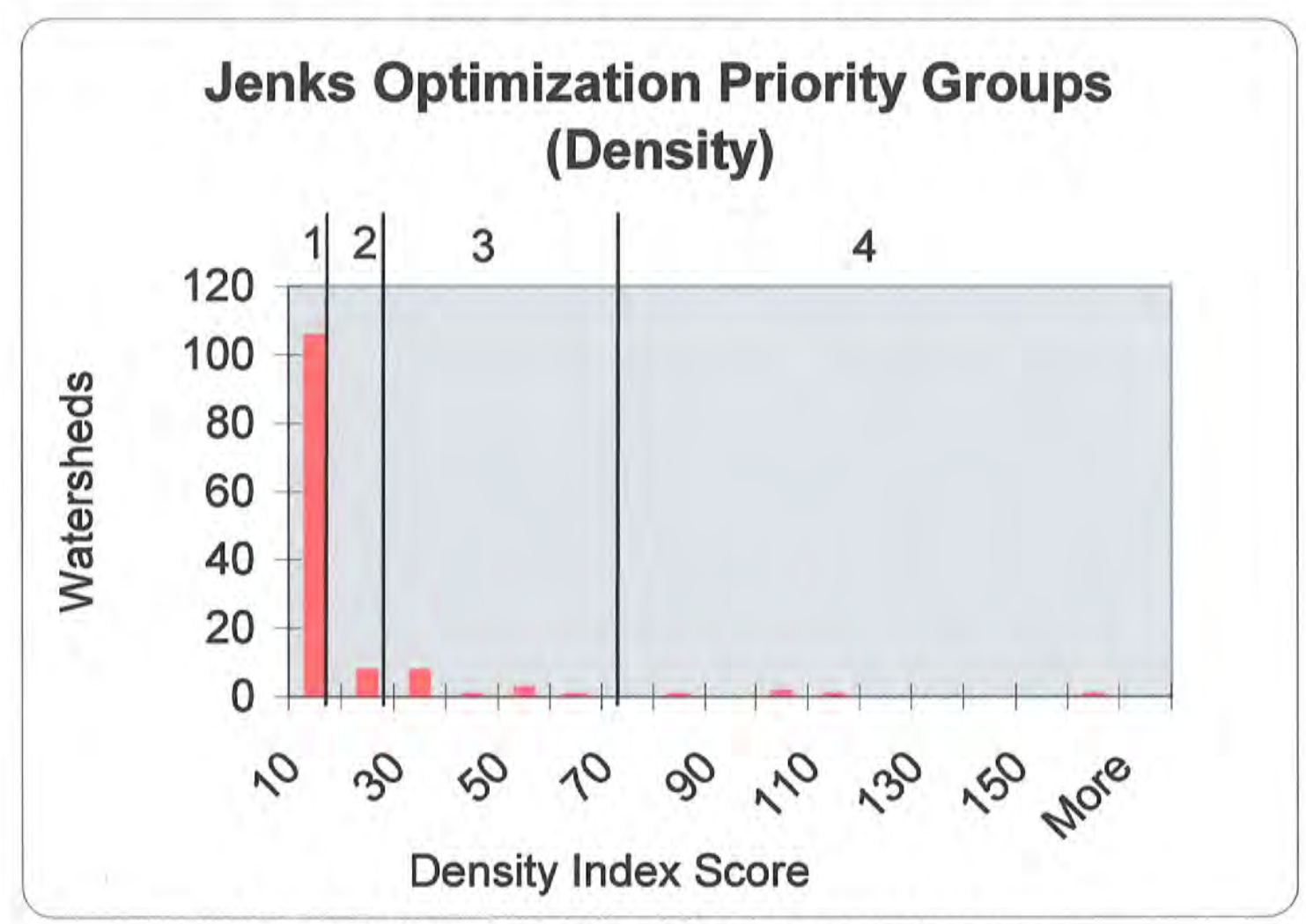

Figure 5.3. Distribution of Screen 2 density scores and final classes.

\subsection{Screen Three}

\subsubsection{Description}

The final screen modifies the ranking by considering statewide issues related to interagency and intra-agency concerns. This screen takes a more qualitative ranking approach, using both GIS and a simple scoring formula. It combines directives of the OPSW and issues relating to ODF operations. Screen three prioritizes watersheds with specific management interest areas to meet operational and legal requirements sooner. It is designed to also allow similar concerns to be easily added into the overall prioritization model. Three specific concerns are currently incorporated into the prioritization model. 


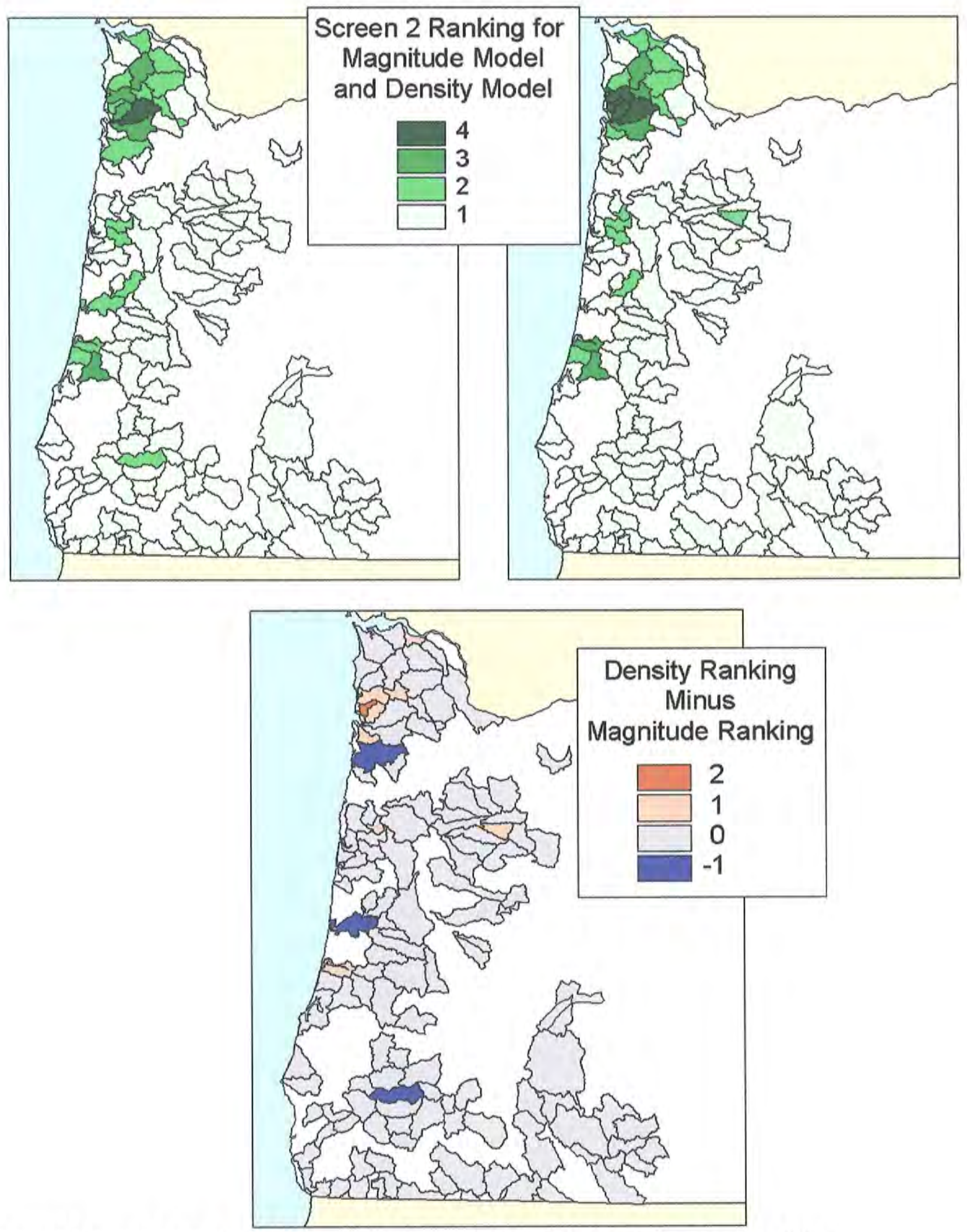

Figure 5.4. Spatial distribution of 2nd screen priority scores. Magnitude score is shown on upper left, Density score is shown on right. Lower map shows difference between Density Model and Magnitude model rankings. 
Oregon Plan Measure IV.A.8 instructs ODFW and OWRD to identify in-stream flow priorities for watershed basins. The priorities are based on the season when instream water rights are not met and areas where fish habitat is most dependent on streamflow restoration. By incorporating these priority streamflow restoration basins into the prioritization model, ODF can take advantage of in-depth analyses already completed by other state agencies.

A study performed by ODFW for ODF identifies salmon anchor habitat areas for Astoria, Forest Grove and Tillamook state forest district watersheds. Salmon anchor habitat is identified as important for short-term conservation of local salmon populations as well as long-term persistence of larger coastal salmon metapopulations. In addition to the benefit of utilizing existing in-depth prioritization studies, incorporation of these studies into ODF's watershed prioritization model satisfies OPSW requirements for ODF to work with other state agencies in protecting salmon habitat.

Several state forest management districts' implementation plans identify municipal drinking water sources as areas requiring special management needs. The Oregon BLM maintains a digital map layer representing municipal water sources. This layer can be used to identify fifth-field watersheds containing municipal water supply areas.

The scoring system is designed to add one point to the $2^{\text {nd }}$ screen score for each of the above concerns that are present within a watershed. This screen allows the overall priority rating to be added to as new resource/contractual concerns are discovered. 


\subsubsection{Techniques}

Using GIS to intersect ODF watersheds with the OWRD priority flow basins layer identified watersheds containing streamflow restoration basins. A watershed was given a point if it contained any part of a streamflow restoration basin. Many watersheds were incorrectly identified and removed because of discrepancies in hydrologic boundaries between layers. Sixty-seven fifth-field watersheds containing ODF lands are identified using this method. The same method was used to identify salmon anchor habitat and municipal watersheds. The points are then added to the second screen score to arrive at a new fifth-field priority score. As water restoration priority basins are added to or removed from OWRD's list, points can be added or removed from the priority score (the same is true for salmon anchor habitats or municipal water sources).

Each fifth-field watershed now has a priority score ranging between 1 and 7 . However, since the watersheds will not be analyzed individually, the priority scores need to be distributed to each Watershed Analysis Unit. Since most WAU's with multiple fifth-fields contain at least one higher priority watershed and usually many other low priority watersheds, the final priority score is calculated as the highest score from among any WAU's constituent fifth-field watersheds. For WAU's comprised of only one fifthfield the score remains the same. This process is done twice to develop an overall magnitude score and a density score. For example, the Siletz watershed analysis unit consists of Rock Creek, Middle Siletz, and Lower Siletz fifth-field watersheds. The third screen magnitude scores for those watersheds are 2, 2, and 4 respectively. The Lower Siletz fifth-field watershed has the highest magnitude score out of the three, therefore the Siletz watershed analysis unit receives a final priority ranking score of 4 . The final 
priority list is a series of groupings. Watershed analysis units with identical scores are considered equal priorities.

The overall spatial distribution of magnitude and density priority scoring for the WAU's is illustrated in Figure 5.5. Tables 5.1 and 5.2 list the WAU's and the final priority magnitude and density scores.

\subsection{Future Priorities}

An important consideration that should be considered in prioritizing watersheds for ODF is the level of management activity expected in the near future. Districts are currently responsible for drafting Implementation plans that describe management approaches used to implement Forest Management Plans and Habitat Conservation Plans. They describe ten-year estimated levels of management activity regarding silvicultural operations, road construction/maintenance, and recreation within district management basins. Most of the implementation plans estimate how many acres of various management operations will occur within each management basin. Most management basins roughly correspond to hydrologic boundaries, so that aggregating the data into larger watersheds is possible. Several challenges exist to quantifying these management levels to compare watersheds across the state.

Some districts' implementation plans do not offer discrete acreage values or do not contain multiple management basins. Tillamook district does not suggest specific acreage amounts for silvicultural activities. Western Lane and Southwest districts are each considered as only one management basin. Coos district does not yet have an implementation plan. 


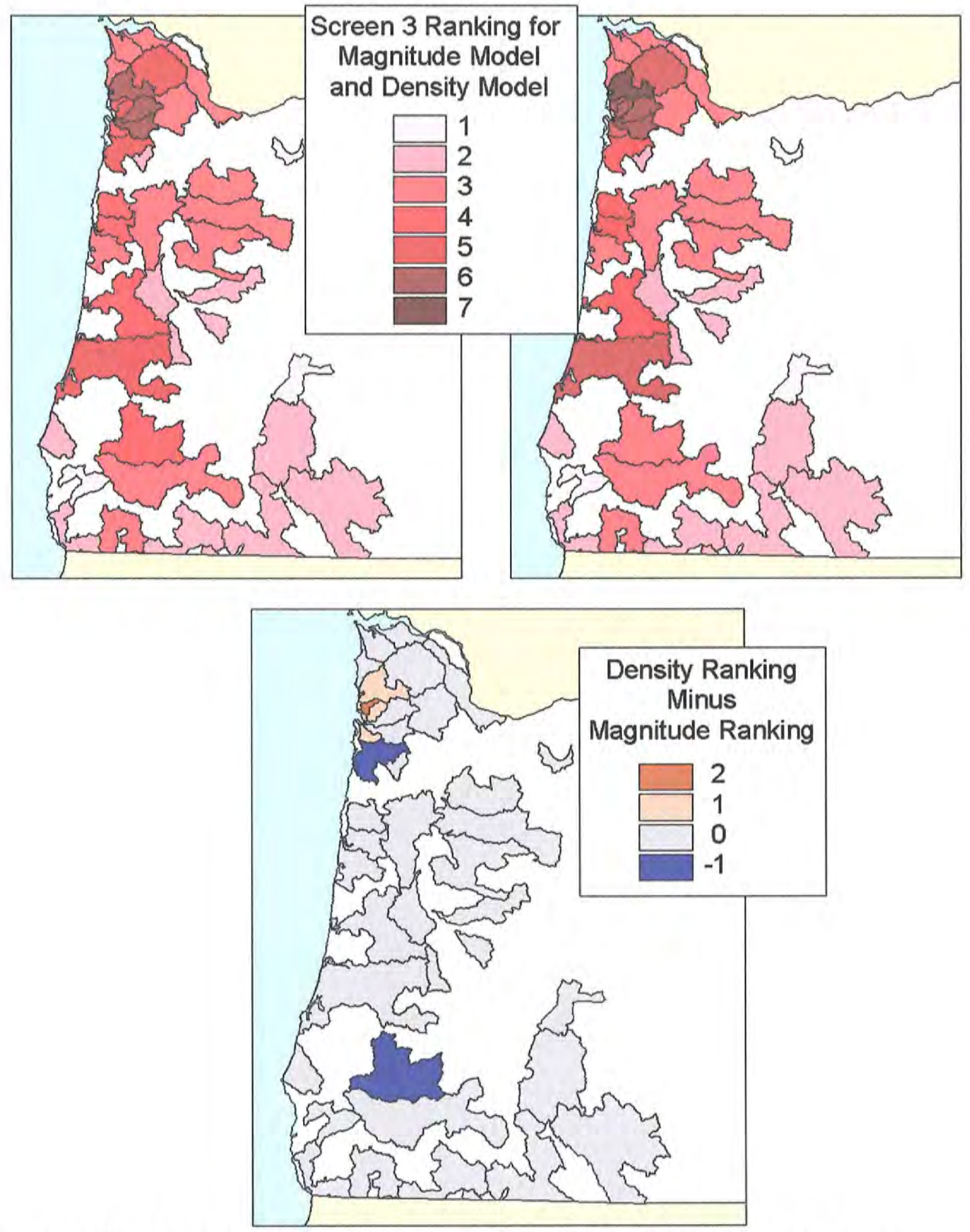

Figure 5.5. Spatial distribution of 3rd screen priority scores for watershed analysis units. Magnitude score is shown on upper left, Density score is shown on upper right. Lower map shows difference between Density and Magnitude rankings. 
Table 5.1. Overall WAU priority ranking for magnitude.

\begin{tabular}{|c|c|}
\hline WAU & $\begin{array}{c}\text { Overall Magnitude } \\
\text { Score }\end{array}$ \\
\hline Lower Nehalem & 6 \\
\hline Trask & 6 \\
\hline Wilson & 6 \\
\hline Kilchis & 5 \\
\hline Elliott State Forest & 5 \\
\hline Upper Nehalem & 5 \\
\hline Nestucca & 5 \\
\hline Miami & 4 \\
\hline Tillamook River & 4 \\
\hline Siletz & 4 \\
\hline Siuslaw & 4 \\
\hline Yaquina & 4 \\
\hline South Umpqua / Cow Creek & 4 \\
\hline Clatskanie & 3 \\
\hline Gnat Creek / Lower Columbia & 3 \\
\hline Lower Alsea & 3 \\
\hline Molalla-Pudding & 3 \\
\hline Necanicum & 3 \\
\hline North Santiam & 3 \\
\hline South Santiam & 3 \\
\hline Upper Illinois & 3 \\
\hline Upper Rogue & 3 \\
\hline Upper Tualatin & 3 \\
\hline Western Willamette Valley & 3 \\
\hline Young's River & 3 \\
\hline Applegate River / Bear Creek & 2 \\
\hline Chetco & 2 \\
\hline Klamath & 2 \\
\hline Long Tom & 2 \\
\hline McKenzie / Willamette Forks & 2 \\
\hline New River / Sixes River & 2 \\
\hline Sprague & 2 \\
\hline Sun Pass State Forest & 2 \\
\hline Willamina Creek & 2 \\
\hline Tillamook Bay & 1 \\
\hline Little Deschutes & 1 \\
\hline Lower Rogue & 1 \\
\hline Salmon & 1 \\
\hline
\end{tabular}


Table 5.2. Overall WAU priority ranking for density.

\begin{tabular}{|l|c|}
\hline WAU & $\begin{array}{c}\text { Overall } \\
\text { Density Score }\end{array}$ \\
\hline Lower Nehalem & 7 \\
\hline Kilchis & 6 \\
Miami & 6 \\
Trask & 6 \\
Wilson & 6 \\
\hline Elliott State Forest & 5 \\
Tillamook River & 5 \\
Upper Nehalem & 5 \\
\hline Nestucca & 4 \\
Siletz & 4 \\
Siuslaw & 4 \\
Yaquina & 4 \\
\hline Clatskanie & 3 \\
Gnat Creek / Lower Columbia & 3 \\
Lower Alsea & 3 \\
Molalla-Pudding & 3 \\
Necanicum & 3 \\
North Santiam & 3 \\
South Santiam & 3 \\
South Umpqua / Cow Creek & 3 \\
Upper Illinois & 3 \\
Upper Rogue & 3 \\
Upper Tualatin & 3 \\
Western Willamette Valley & 3 \\
Young's River & 3 \\
\hline Applegate River / Bear Creek & 2 \\
Chetco & 2 \\
Klamath & 2 \\
Long Tom & 2 \\
McKenzie / Willamette Forks & 2 \\
New River / Sixes River & 2 \\
Sprague & 2 \\
Sun Pass State Forest & 2 \\
Tillamook Bay & 2 \\
Willamina Creek & 2 \\
\hline Little Deschutes & 1 \\
Lower Rogue & \\
Salmon & 3 \\
\hline
\end{tabular}


The implementation plans may be more useful when more detailed estimates of management activity are published for all districts. Since the data is incomplete, nonuniform, or absent for many of the districts, these values are not currently used in the prioritization process.

\subsection{Limitations of the Prioritization Models}

Both prioritization models attempt to rank watersheds based on specific goals. The goals and issues the model addresses are, in order of importance, ODF management needs, level of ODF influence in the watershed, and potential risks to salmon stocks and clean water with regards to forest management activities. I believe the models currently give a fair assessment of those needs, however there are several issues and assumptions that need to be considered in judging the accuracy of the models.

The first screen attempts to estimate the potential risks to salmon stocks and water quality due to forest management activities. It measures threatened and endangered salmonid species, failed clean water standards, debris flow hazard, and forest road density. It is difficult to determine the exact level of influence any one of these factors may have in a watershed. Most likely, different factors are more important than others in different watersheds. For simplicity of scoring, I considered each of these issues as equally important in determining potential risk. The first screen does not differentiate watersheds dominated by forest management from watersheds with little forest management activity. The model could be improved if a certain factor were found to be more important than the others. For example, if debris flow hazard was shown to be highly correlated with diminished water quality and reduced fish populations, then the 
measurement for high risk debris flow areas might be multiplied by some appropriate factor to more accurately prioritize those watersheds.

The second screen contains an important limitation regarding the number of classes into which watersheds are grouped. With too few classes there is the risk of not properly distinguishing watershed priorities. In effect, the first screen scores would become meaningless. It would also make the third screen score a too dominant factor in prioritizing watersheds, especially as new management issues were included into the third screen. However, having too many classes would negate the effects of the third screen in that a watershed containing all of ODF's mandated and management priorities would not be able to overcome a watershed with just a higher percentage of ODF land. To improve the accuracy of the second screen, extra classes should be added as issues are added to the third screen.

The third screen also runs into the problem of quantifying management issues. Currently, the model calculates flow restoration priorities, salmon anchor habitat, and municipal water sources as equal in importance. Land managers will need to assess whether those issues and goals are equally important or whether some issues should be counted higher than others. As mentioned before, there is also the risk of adding too many issues onto the third screen score. As more issues, in the form of points, are added to the third screen it diminishes the importance of the $1^{\text {st }}$ and $2^{\text {nd }}$ screens.

There is a broad geographic range and considerable differences in physiography of the watersheds being compared in this project. As the model is currently calibrated, with equal weighting factors and four general classes, I think the model reasonably reflects watershed analysis priorities for ODF. 


\section{CONCLUSION}

The Oregon Plan for Salmon and Watersheds defines roles and establishes context for state agencies to aid in the rehabilitation of declining salmon stocks. The Oregon Department of Forestry is beginning to develop a procedure to use watershed analysis to meet ODF management needs and the needs of the OPSW. This project accomplishes four main goals that assist ODF in meeting its objectives.

Analysis using Geographic Information System identifies 132 fifth-field watersheds containing ODF lands. Of these 132 watersheds, 125 are known to contain ODF lands, while seven may need ground surveys to identify property and watershed boundaries. Several maps located in this document and at ODF offices in Salem graphically display the distribution of state forestlands within watersheds across the state.

The data standards outlined in the Oregon Watershed Assessment Manual are used as the baseline criteria to assess data applicability to ODF's watershed analysis needs. An assessment matrix is designed that summarizes the data requirements of the OWAM into fifty information items. Over half of these requirements are met by available data sources located at ODF, online, or from other state agencies. Some watershed specific data is difficult to gather and assess because the information is located in many different places and/or the time needed to acquire the information is beyond the scope of this project. I recommend that ODF contact the watershed council and/or agency to acquire further data when each watershed analysis is in the planning stage. It may also be useful to ODF, other state agencies, and the public to design a watershed analysis summary that outlines key findings in each of ODF's completed analyses. 
Over 200 OWEB and federal watershed assessments and analyses were collected in either digital or hardcopy format. These documents are useful to identify what data and analyses have already been done for a specific watershed. Locations of data and documents are organized in a relational database with graphic user interfaces that allow users to query, edit, and update tables. There is also a reporting function that allows users to generate a list of data and documents related to specific ODF watershed analysis units. There is a user manual associated with the database that lists step-by-step instructions on the major functions of the database.

The final goal of the project is to prioritize watershed analysis needs. The prioritization model uses three screens that address ODF management needs, level of ODF influence in each watershed, and several specific management goals associated with forestry operations and other state agencies. Two different prioritization methodologies rank watersheds based on the density or the magnitude of indicators within each watershed. There are several weighting and classification factors that may be better calibrated as new evidence and management needs are identified. The prioritization method assists ODF in achieving State Board of Forestry and Oregon Plan goals of increasing salmon populations and improving water quality in Oregon watersheds. 


\section{REFERENCES}

Governor's Watershed Enhancement Board. 1997. Oregon Coastal Salmon Restoration Initiative - Final Plan.

Available: http://www.oregon-plan.org/archives/index.html

Govemor's Watershed Enhancement Board. 1997. Steelhead Supplement to the OCSRI. Available: http://www.oregon-plan.org/archives/index.html

Greenberg, J. and Welch, K.F. 1998. Hydrologic Process Identification for Western Oregon. Prepared for Boise Cascade Corp., Boise, Idaho.

Jenks, G. F. 1967. The Data Model Concept in Statistical Mapping. International Yearbook of Cartography, (7) 186-190.

Kitzhaber, J. A. 1999. The Oregon Plan for Salmon and Watersheds. Executive Order No. EO 99-01. Salem, Oregon

Osaragi, T. 2002. Classification Methods For Spatial Data Representation. University College London, London, England.

Regional Interagency Executive Committee. 1995. Ecosystem Analysis at the Watershed Scale (Federal Guide for Watershed Analysis, version 2.2). Regional Ecosystem Office, Portland, Oregon.

Watershed Professional Network. 1999. Oregon Watershed Assessment Manual. Prepared for the Governor's Watershed Enhancement Board, Salem, Oregon. 


\section{Appendix A: Table of fifth-field watersheds that contain state forestlands.}

\begin{tabular}{|c|c|c|c|}
\hline WATERSHED NAME & ACRES & ODF ACRES & PERCENT ODF \\
\hline KILCHIS RIVER & 41,581 & 34,846 & 83.8039 \\
\hline WILSON RIVER & 122,934 & 96,781 & 78.7259 \\
\hline COOK CREEK / LOWER NEHALEM RIVER & 67,960 & 44,470 & 65.4349 \\
\hline MIAMI RIVER & 23,053 & 13,921 & 60.3859 \\
\hline SALMONBERRY RIVER & 45,583 & 26,687 & 58.5468 \\
\hline TRASK RIVER & 112,041 & 64,735 & 57.7781 \\
\hline LOWER NEHALEM RIVER & 113,887 & 56,600 & 49.6984 \\
\hline MIDDLE NORTH SANTIAM RIVER & 56,694 & 22,529 & 39.7382 \\
\hline WEST FORK MILL!COMA RIVER & 96,690 & 37,114 & 38.3841 \\
\hline PLYMPTON CREEK & 31,964 & 11,477 & 35.9078 \\
\hline NORTH FORK NEHALEM RIVER & 62,253 & 21,108 & 33.9068 \\
\hline LOWER UMPQUA RIVER & 56,500 & 18,941 & 33.5247 \\
\hline UMPQUA DUNES / TENMILE FRONTAL & 64,819 & 21,561 & 33.2635 \\
\hline ROCK CREEK / SILETZ RIVER & 27,632 & 6,914 & 25,0200 \\
\hline BIG CREEK / GNAT CREEK & 76,965 & 18,676 & 24.2658 \\
\hline MIDDLE NEHALEM RIVER & 112,587 & 26,226 & 23.2937 \\
\hline UPPER NEHALEM RIVER & 142,742 & 32,899 & 23.0478 \\
\hline GALES CREEK & 60,320 & 13,765 & 22.8207 \\
\hline UPPER YAQUINA RIVER & 53,145 & 9,116 & 17.1541 \\
\hline TILLAMOOK BAY & 12,242 & 1,950 & 15.9322 \\
\hline BIG ELK CREEK & 56,996 & 9,011 & 15.8105 \\
\hline UPPER KLAMATH LAKE & 122,721 & 15,709 & 12.8007 \\
\hline WILDCAT CREEK & 34,913 & 4,456 & 12.7623 \\
\hline LAKE CREEK & 74,497 & 9,340 & 12.5377 \\
\hline SCOGGINS CREEK & 87,074 & 10,147 & 11.6537 \\
\hline MILL CREEK / UMPQUA RIVER & 85,959 & 9,237 & 10.7454 \\
\hline ABIQUA CREEK & 104,757 & 9,940 & 9.4883 \\
\hline TILLAMOOK RIVER & 38,917 & 3,465 & 8.9036 \\
\hline YOUNGS RIVER & 133,060 & 10,925 & 8.2107 \\
\hline MIDDLE COW CREEK & 113,151 & 7,307 & 6.4577 \\
\hline LOWER SIUSLAW RIVER & 108,080 & 6,607 & 6.1133 \\
\hline NESTUCCA RIVER & 164,108 & 8,833 & 5.3825 \\
\hline WILLIAMSON RIVER ABOVE SPRAGUE RIVER & 114,297 & 5,921 & 5,1803 \\
\hline LOWER COOS RIVER / COOS BAY & 134,550 & 6,953 & 5.1675 \\
\hline DETROIT RESERVOIR / BLOW OUT DIVIDE CREEK & 74,155 & 3,319 & 4.4761 \\
\hline MARY'S RIVER & 193,146 & 7,716 & 3.9949 \\
\hline CLATSKANIE RIVER & 61,522 & 2,302 & 3.7416 \\
\hline SUNSET PRAIRIE & 48,596 & 1,783 & 3.6698 \\
\hline DIAMOND CREEK & 19,272 & 574 & 2.9804 \\
\hline UPPER MOLALLA RIVER & 129,367 & 3,710 & 2.8679 \\
\hline DEADWOOD CREEK & 37,504 & 1,003 & 2.6749 \\
\hline LITTLE NORTH SANTIAM RIVER & 72,363 & 1,883 & 2.6018 \\
\hline NECANICUM RIVER & 83,605 & 2,044 & 2.4444 \\
\hline GRAVE CREEK & 104,531 & 2,382 & 2.2785 \\
\hline WOLF CREEK & 37,905 & 845 & 2.2303 \\
\hline ALTHOUSE CREEK & 29,686 & 642 & 2.1619 \\
\hline LOWER NORTH SANTIAM RIVER & 80,201 & 1,728 & 2.1543 \\
\hline THOMAS CREEK & 92,480 & 1,923 & 2.0793 \\
\hline LITTLE NESTUCCA RIVER & 38,910 & 791 & 2.0326 \\
\hline
\end{tabular}




\begin{tabular}{|c|c|c|c|}
\hline WATERSHED NAME & ACRES & ODF ACRES & PERCENT ODF \\
\hline CRABTREE CREEK & 99,919 & 1,814 & 1.8151 \\
\hline DEER CREEK & 72,680 & 1,303 & 1.7930 \\
\hline LOBSTER CREEK & 44,167 & 649 & 1.4700 \\
\hline LOWER SILETZ RIVER & 80,121 & 1,117 & 1.3942 \\
\hline UPPER COW CREEK & 47,483 & 652 & 1.3741 \\
\hline ROGUE RIVER / TAYLOR CREEK & 93,430 & 1,206 & 1.2913 \\
\hline LUCKIAMUTE RIVER & 201,424 & 2,562 & 1.2722 \\
\hline WEST FORK COW CREEK & 55,914 & 613 & 1.0969 \\
\hline ILLINOIS RIVER / LAWSON CREEK & 41,204 & 373 & 0.9058 \\
\hline WINBERRY CREEK & 40,228 & 342 & 0.8513 \\
\hline WEST FORK ILLINOIS RIVER & 77,064 & 617 & 0.8012 \\
\hline WILLAMINA CREEK & 53,709 & 430 & 0.7999 \\
\hline LOWER KLAMATH LAKE & 300,378 & 2,298 & 0.7651 \\
\hline ROGUE RIVER / KELSEY CREEK & 104,189 & 794 & 0.7621 \\
\hline DRIFT CREEK & 44,304 & 330 & 0.7443 \\
\hline CHETCO RIVER & 36,200 & 260 & 0.7190 \\
\hline BEAVER CREEK / WALDPORT BAY / VINGIE CREEK & 32,488 & 231 & 0.7112 \\
\hline KLAMATH RIVER / SHOVEL CREEK & 186,610 & 1,223 & 0.6552 \\
\hline UPPER SIUSLAW RIVER & 127,736 & 750 & 0.5872 \\
\hline LONG TOM RIVER & 262,849 & 1,523 & 0.5794 \\
\hline DAIRY CREEK & 147,948 & 767 & 0.5186 \\
\hline BUTTE CREEK & 214,437 & 1,081 & 0.5041 \\
\hline ROGUE RIVER / ILLAHE CREEK & 45,076 & 226 & 0.5005 \\
\hline SPRAGUE RIVER VALLEY & 309,065 & 1,531 & 0.4955 \\
\hline UPPER APPLEGATE RIVER & 142,466 & 656 & 0.4602 \\
\hline $\begin{array}{l}\text { MIDDLE FORK WILLAMETTE RIVER / LOOKOUT POINT } \\
\text { RESERVOIR }\end{array}$ & 67,294 & 306 & 0.4552 \\
\hline LITTLE APPLEGATE RIVER & 72,383 & 320 & 0.4424 \\
\hline WHISKEY CREEK & 44,430 & 196 & 0.4422 \\
\hline WINCHUCK RIVER & 45,781 & 197 & 0.4297 \\
\hline SILVER CREEK / PUDDING RIVER & 145,459 & 619 & 0.4256 \\
\hline MIDDLE SILETZ RIVER & 41,435 & 174 & 0.4198 \\
\hline MIDDLE UMPQUA RIVER & 63,482 & 247 & 0.3891 \\
\hline MCKENZIE RIVER / ELK CREEK & 20,662 & 80 & 0.3881 \\
\hline SPRAGUE RIVER ABOVE SYCAN RIVER & 64,862 & 246 & 0.3789 \\
\hline LOWER MCKENZIE RIVER & 164,619 & 620 & 0.3769 \\
\hline UPPER NORTH SANTIAM RIVER & 144,248 & 543 & 0.3765 \\
\hline SIXES RIVER & 85,903 & 308 & 0.3584 \\
\hline SOUTH FORK SPRAGUE RIVER & 82,212 & 281 & 0.3414 \\
\hline LOWER YAQUINA RIVER & 45,956 & 152 & 0.3300 \\
\hline WILLIAMSON RIVER AT KLAMATH MARSH & 521,276 & 1,695 & 0.3251 \\
\hline SYCAN RIVER ABOVE SPRAGUE RIVER & 148,395 & 469 & 0.3163 \\
\hline UPPER LITTLE DESCHUTES & 63,100 & 198 & 0.3140 \\
\hline MILL CREEK / WILLAMETIE RIVER & 71,232 & 220 & 0.3093 \\
\hline ELK CREEK / ROGUE RIVER & 85,494 & 233 & 0.2723 \\
\hline TRAIL CREEK & 35,345 & 79 & 0.2233 \\
\hline LOWER ALSEA RIVER & 96,008 & 204 & 0.2121 \\
\hline MIDDLE SOUTH UMPQUA RIVER / RICE CREEK & 59,442 & 121 & 0.2032 \\
\hline LOST RIVER & 489,759 & 920 & 0.1878 \\
\hline NORTH FORK SPRAGUE RIVER & 133,292 & 240 & 0.1799 \\
\hline BEAR CREEK & 231,472 & 394 & 0.1702 \\
\hline
\end{tabular}




\begin{tabular}{|c|c|c|c|}
\hline WATERSHED NAME & ACRES & ODF ACRES & PERCENT ODF \\
\hline LOWER COW CREEK & 102,537 & 171 & 0.1671 \\
\hline NEW RIVER & 98,900 & 165 & 0.1668 \\
\hline YACHATS RIVER & 27,759 & 45 & 0.1608 \\
\hline BLUE RIVER & 59,298 & 89 & 0.1506 \\
\hline ROGUE RIVER / SAVAGE CREEK & 53,708 & 78 & 0.1460 \\
\hline LOWER LITTLE DESCHUTES & 99,186 & 145 & 0.1457 \\
\hline JUMPOFF JOE CREEK & 69,783 & 89 & 0.1272 \\
\hline HAMILTON CREEK / SOUTH SANTIAM RIVER & 119,094 & 150 & 0.1256 \\
\hline ROGUE RIVER / REESE CREEK & 74,319 & 80 & 0.1075 \\
\hline EVANS CREEK & 143,447 & 142 & 0.0993 \\
\hline SALMON RIVER & 73,708 & 70 & 0.0956 \\
\hline COTTONWOOD CREEK & 120,283 & 108 & 0.0896 \\
\hline ELK CREEK / UMPQUA RIVER & 187,321 & 156 & 0.0832 \\
\hline SOUTH UMPQUA RIVER & 141,575 & 115 & 0.0809 \\
\hline KLAMATH LAKE & 265,836 & 200 & 0.0752 \\
\hline SUCKER CREEK & 62,207 & 40 & 0.0638 \\
\hline SPRAGUE RIVER ABOVE WILLIAMSON RIVER & 83,095 & 51 & 0.0612 \\
\hline JENNY CREEK & 134,398 & 78 & 0.0583 \\
\hline ILLINOIS RIVER / JOSEPHINE CREEK & 81,795 & 39 & 0.0472 \\
\hline UPPER COAST FORK WILLAMETTE RIVER & 97,467 & 38 & 0.0389 \\
\hline LOWER NORTH UMPQUA RIVER & 106,260 & 40 & 0.0378 \\
\hline SCAPPOOSE CREEK & 213,394 & 79 & 0.0370 \\
\hline BIG BUTTE CREEK & 158,384 & 40 & 0.0253 \\
\hline UPPER UMPQUA RIVER & 169,561 & 42 & 0.0245 \\
\hline CALAPOOIA RIVER & 183,286 & 40 & 0.0221 \\
\hline OLLALA CREEK / LOOKINGGLASS CREEK & 103,183 & 11 & 0.0110 \\
\hline INDIGO CREEK & 49,016 & 5 & 0.0103 \\
\hline PISTOL RIVER & 66,886 & 7 & 0.0101 \\
\hline QUARTZVILLE CREEK & 109,252 & 8 & 0.0070 \\
\hline MIDDLE LITTLE DESCHUTES RIVER & 65,376 & 4 & 0.0058 \\
\hline UPPER NORTH FORK SMITH RIVER & 51,778 & 3 & 0.0057 \\
\hline RICKREALL CREEK & 117,196 & 1 & 0.0011 \\
\hline UPPER SMITH RIVER & 95,588 & $<1$ & 0.0002 \\
\hline
\end{tabular}


Appendix B: Data Assessment Matrix 


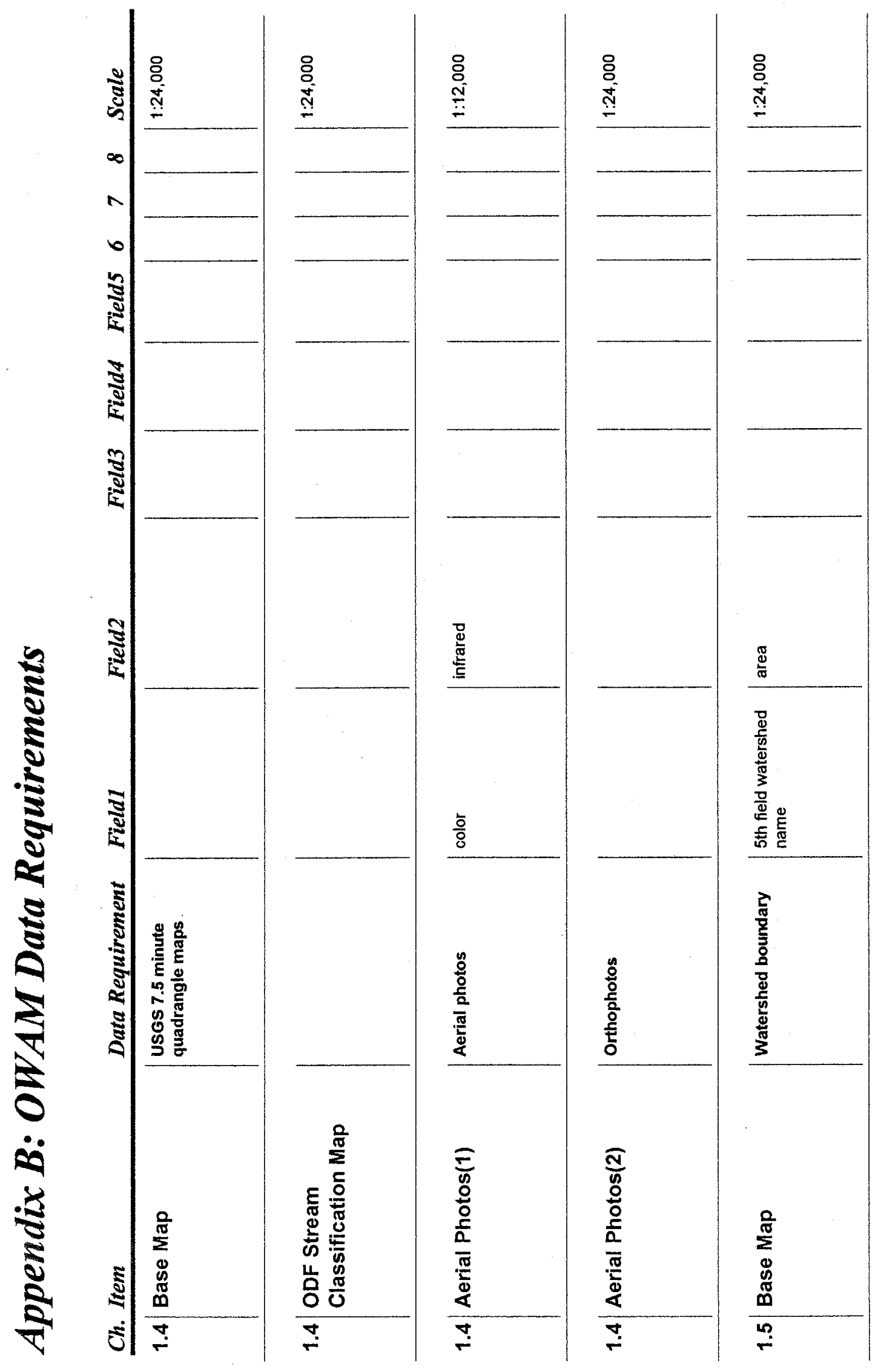




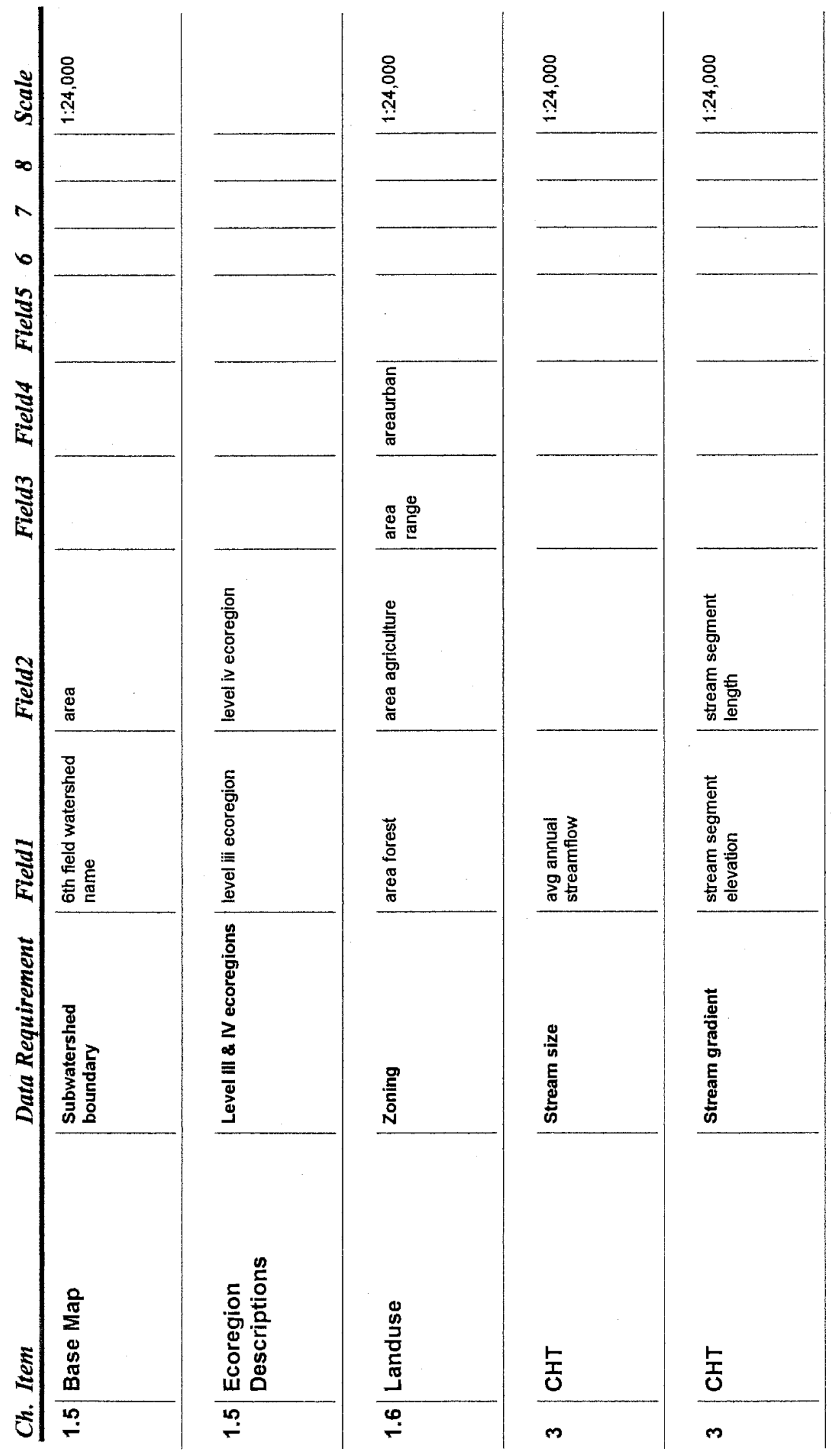




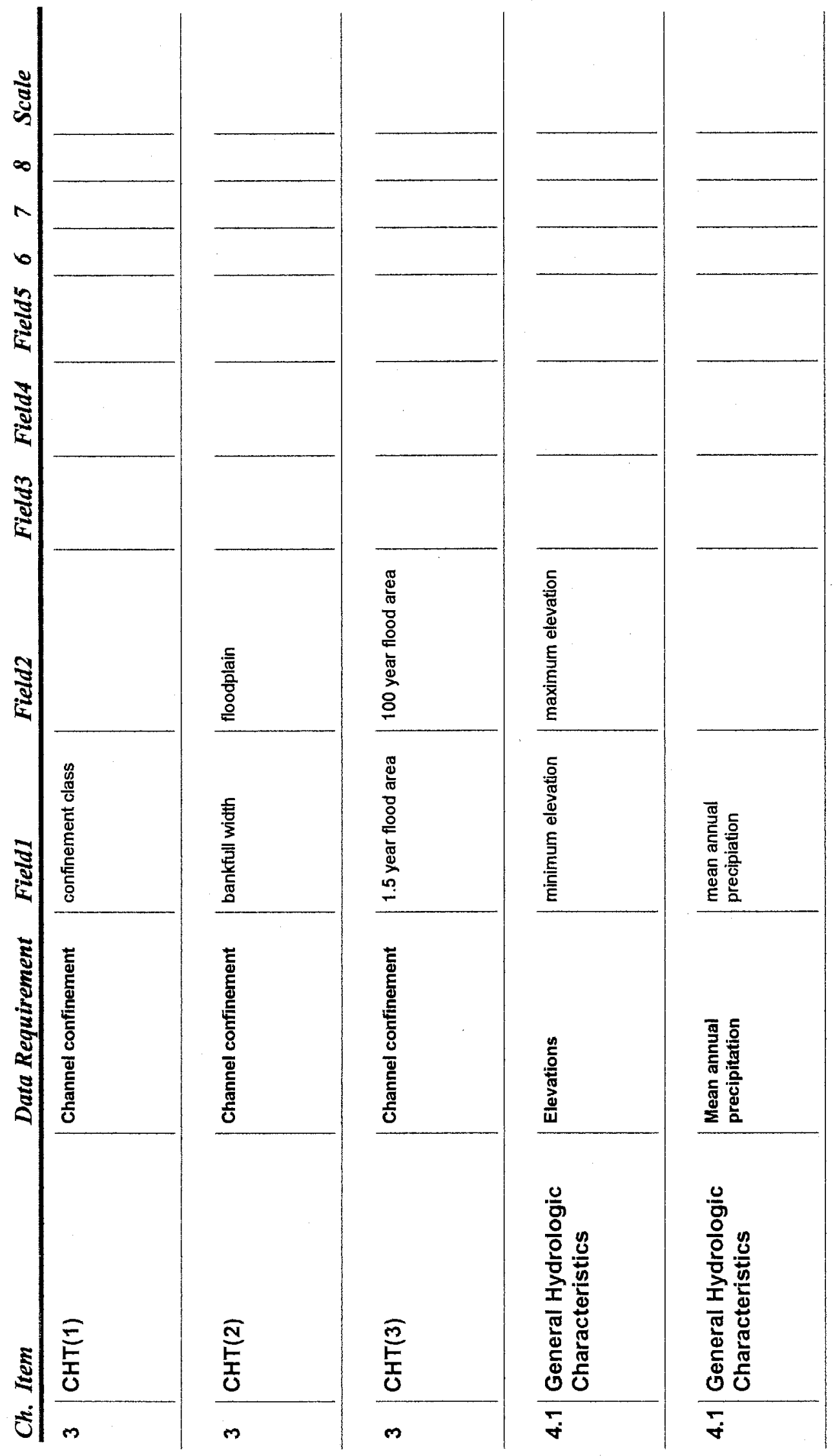




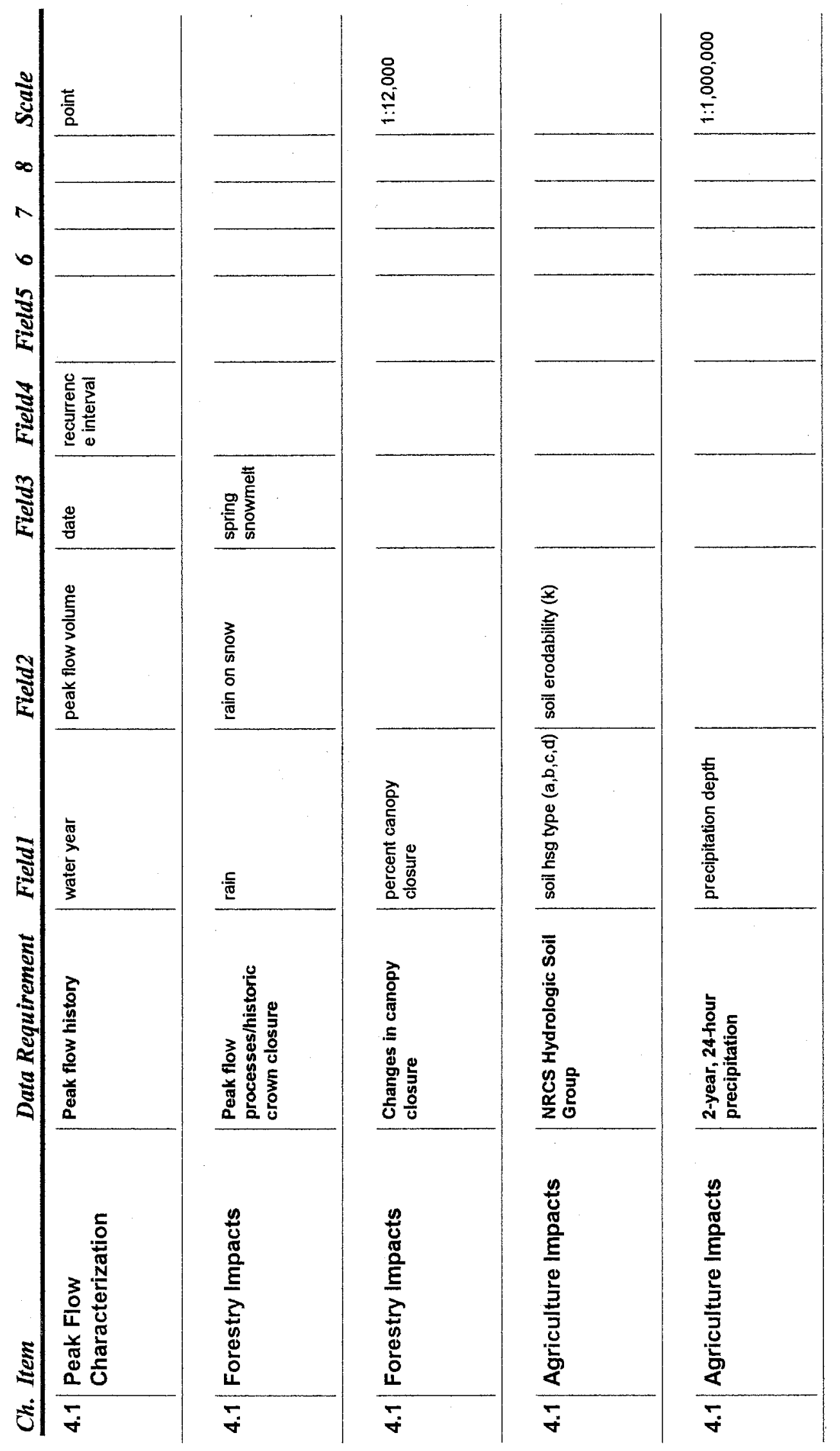



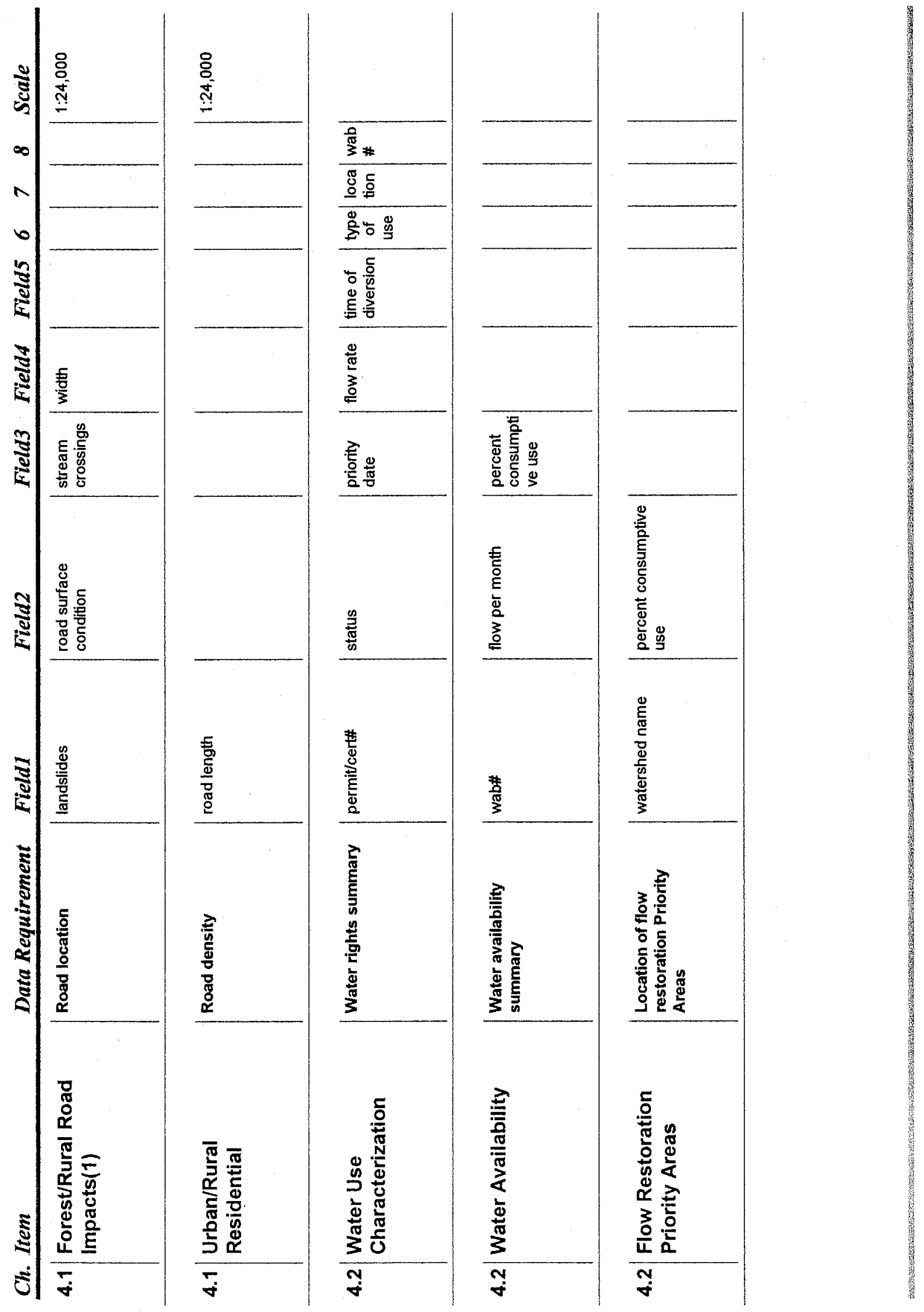


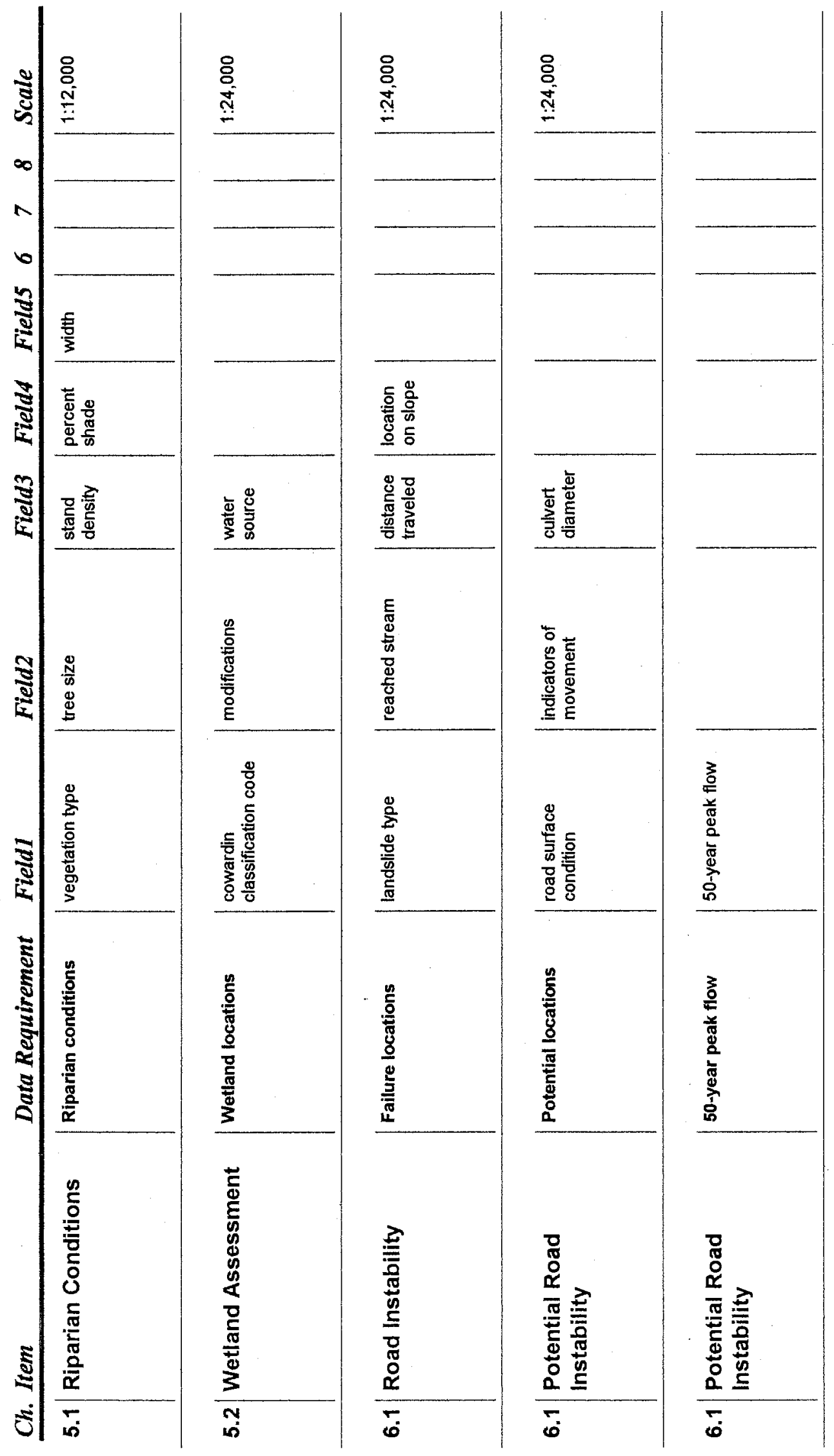




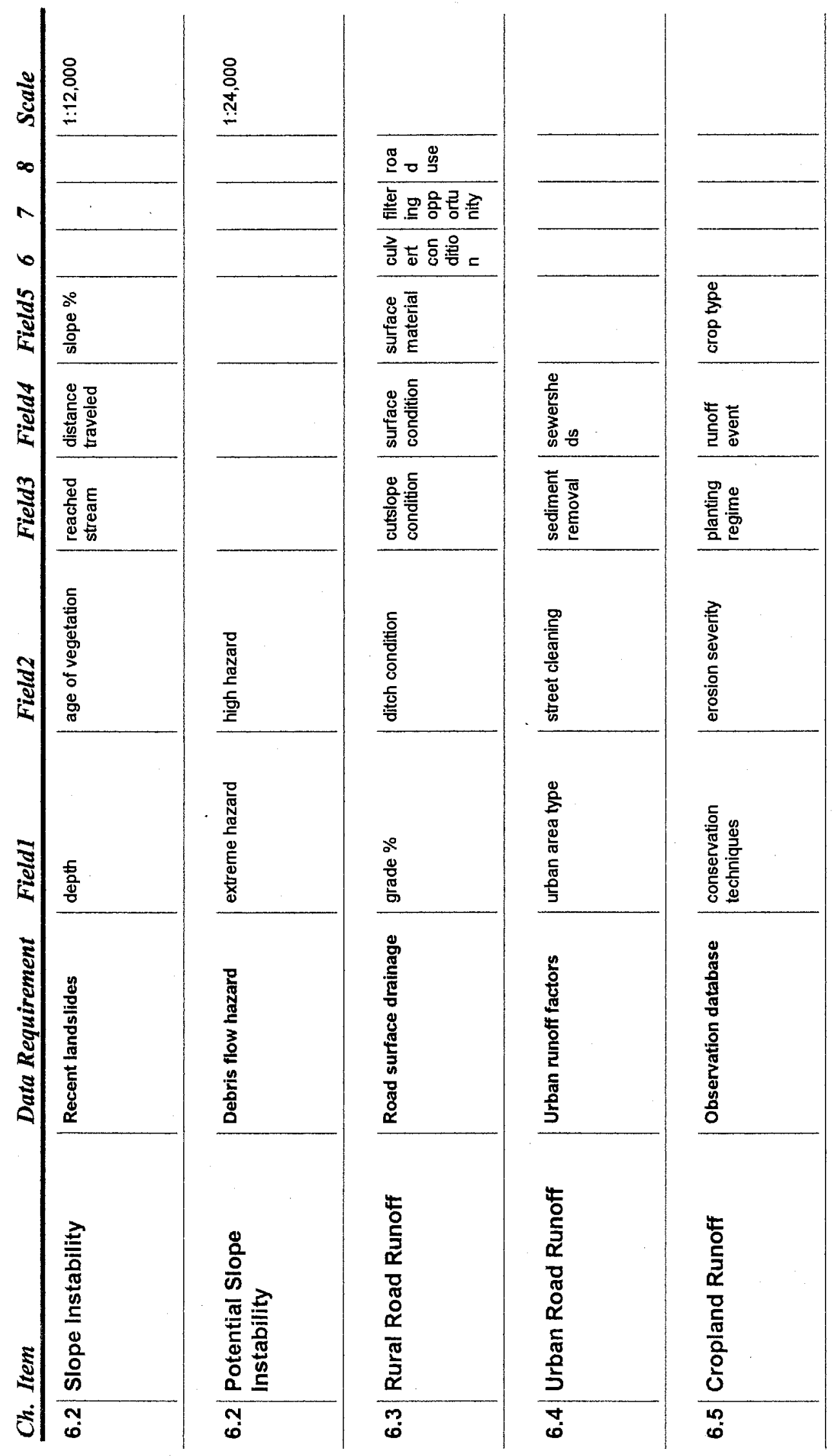



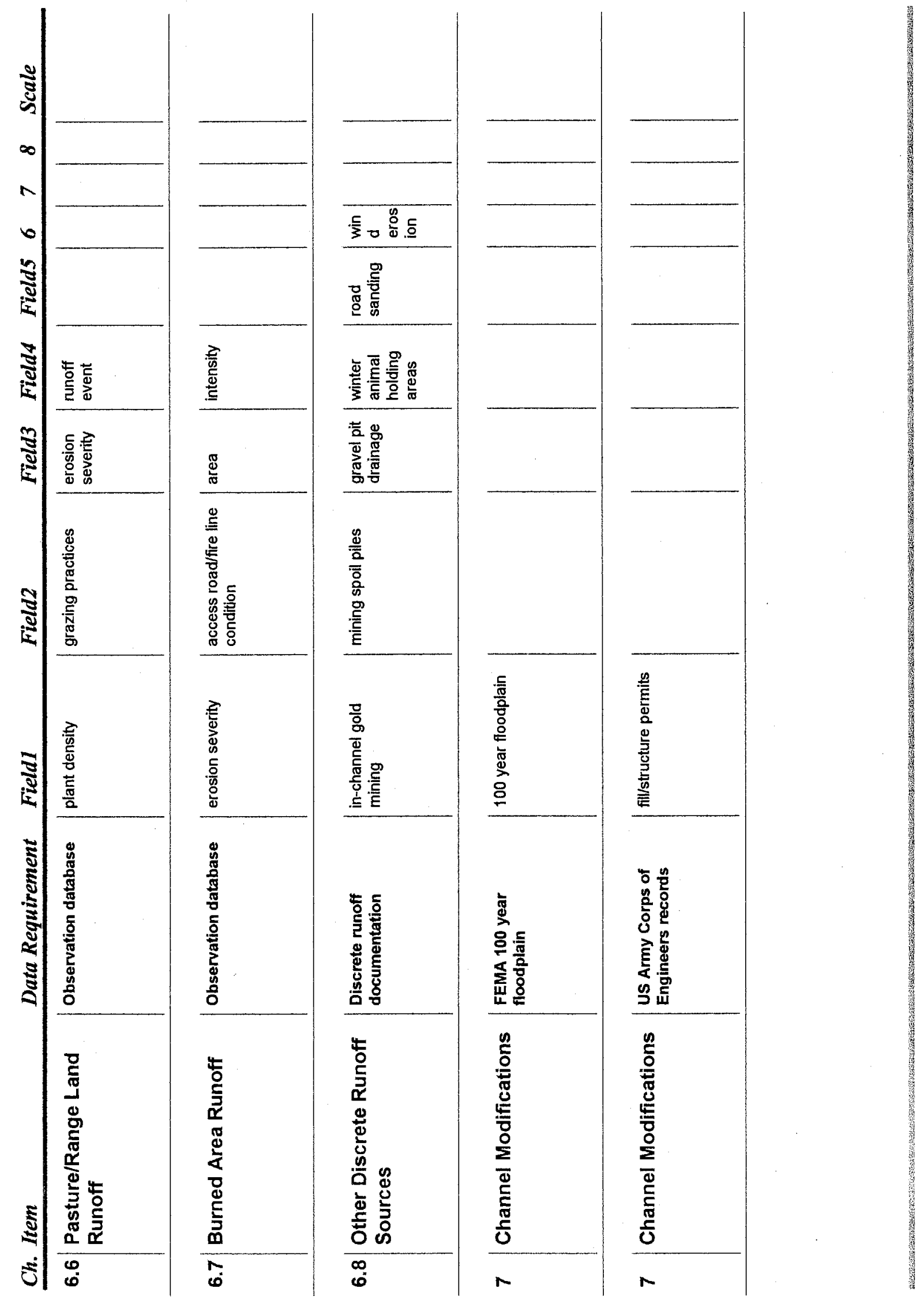


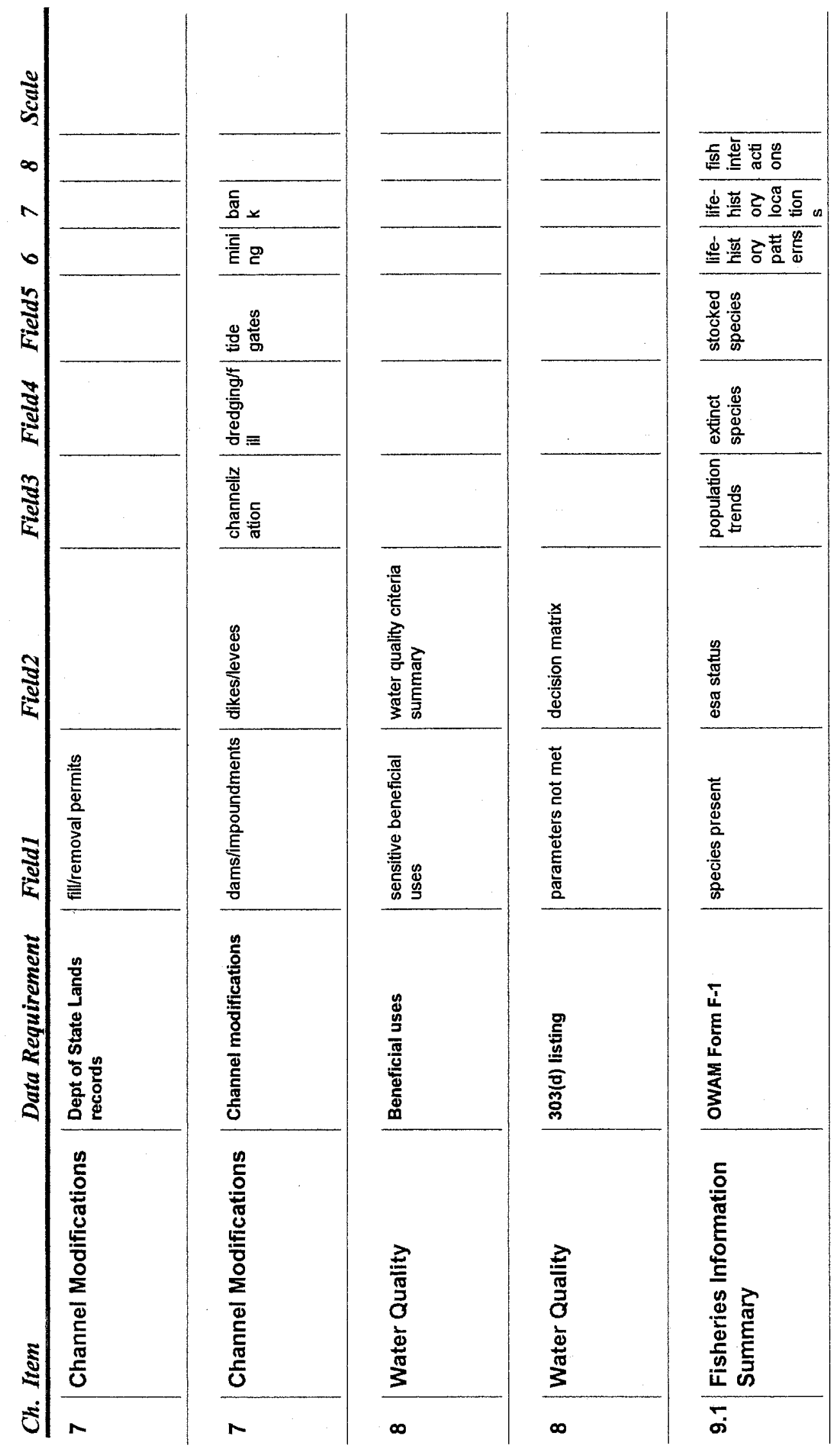




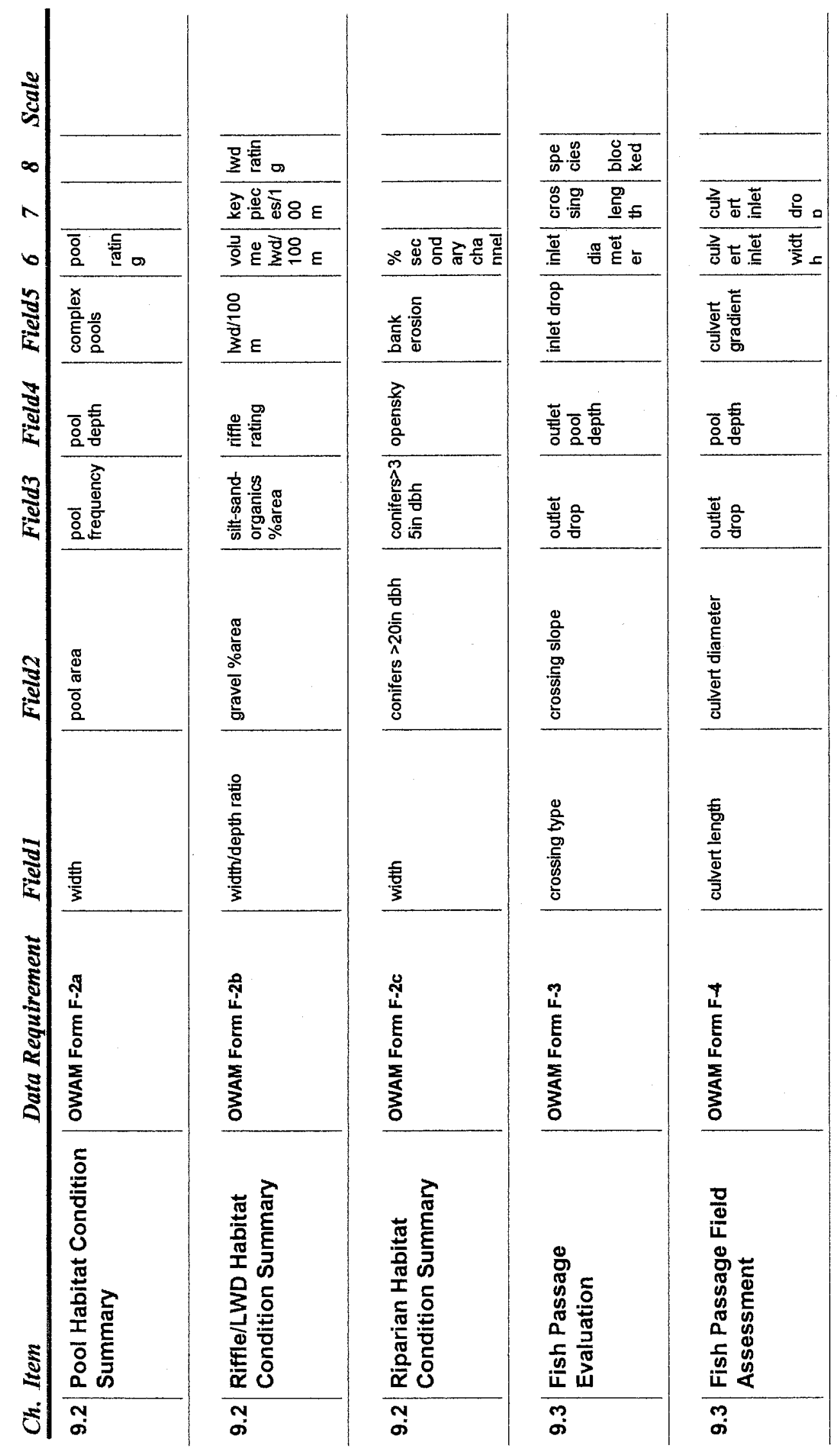


Appendix C: Watershed Database Users Manual 


\title{
Watershed Database User Manual
}

\author{
Oregon Department of Forestry
}

October 2002

Josh Darling

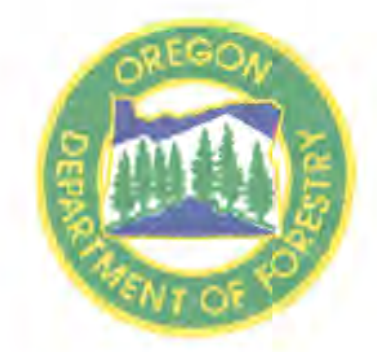

\section{Table of Contents}

I. Overview

II. Finding/editing/entering data with Entry Forms

III. Generating document and data Reports

IV. View database contents

V. Updating $5^{\text {th }}$ field watersheds within Watershed Analysis Units

VI. Watershed / District locator map 


\section{Overview}

The Watershed Information Database is designed to assist ODF watershed analysis projects by organizing documents and data by region and generating reports for ODF watershed analysis units (WAU's). The database was created using Microsoft Access 97 software, familiarity with the main Access database window and section tabs is desirable. If the database is imported into Access 2000 or another database program, instructions and interface illustrations in this user manual may not apply.

Figure 1 illustrates how tables and queries are linked together within the database. The green boxes represent tables that can be added to or edited. Red ovals represent user interface forms where most database interaction will occur.

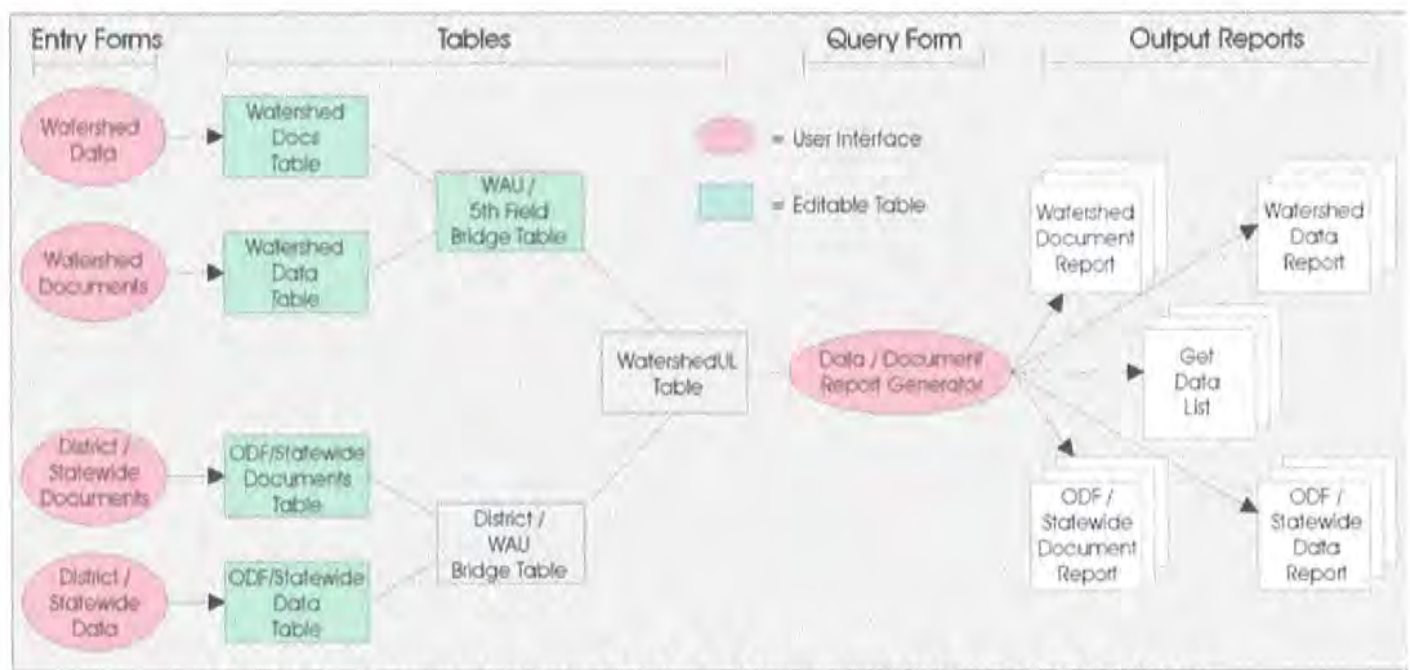

Figure 1. Schematic diagram of the Watershed Information Database.

The database organizes data into four main tables:

- ODF/Statewide Data

- ODF/Statewide Documents

- Watershed Data

- Watershed Documents

The ODF/Statewide Data table contains records of GIS, tabular, image, and other types of data available at the district or statewide scale. The fields that describe each record include title, file name, originator, scale, location, custodian, etc.

The ODF/Statewide Documents table contains records of documents that cover statewide or district areas. Fields include title, author, publication date, location, etc. 
The Watershed Data table contains records of data that are linked to specific watersheds. Fields are similar to the ones described in ODF/Statewide data table above.

The Watershed Docs table contains records of documents that pertain to specific watersheds. Fields are similar to the ones described in ODF/Statewide document table above.

Each of the tables has a corresponding Entry form to find, edit, and enter new records (see figure 1).

The Document/Data Report Generator is a query-based form that allows the user to choose a WAU on which to generate reports. This form works by querying and updating the WatershedUL table linked to the two bridge tables. The form allows the user to make five different reports: ODF/Statewide Documents, ODF/Statewide Data, Watershed Documents, Watershed Data, and the Get Data List, a list that is used for locating and gathering data for distribution.

\section{Finding/Editing/Entering new data using Entry Forms}

This section describes how to find and/or edit data and documents in the database and how to enter new data and documents. Some explanation of vocabulary terms is useful to clarify this section. An 'item' is a document or piece of data that you want to find, edit, or enter in the database. Within Access, each item is stored as a 'record' that contains multiple 'fields'. When you create or edit a record you are adding or changing field values for that record. The forms are arranged so that the user sees all the fields for one record at a time. On the form interface and in this text 'entries' refers to any or all of the fields for one record.

Four different tables are used to store items. New items should only be entered in one table. Each table has a corresponding form for finding and adding new items. Listed below are criteria to help decide which form should be used to enter a new item or find an existing item.

Criteria to determine appropriate entry form:

1. Is the item a document or data? A document can be hardcopy or digital. Examples of documents include analyses, assessments, studies, methodologies, models, management plans, protocols, etc. Examples of data include GIS layers, tabular data, databases, lists, maps, imagery, surveys, etc.

2. Does the item pertain to a specific watershed/watersheds and can those watersheds be identified in terms of their fourth or fifth field names? Does the item pertain to a regional or statewide scale or can it be associated with ODF district areas? If it is hydrologically defined, does it pertain to many or most state or ODF watersheds? 
Table 1 is a matrix to determine the appropriate entry form from the above criteria.

Table 1. Criteria for choosing form to find, edit, or enter information in the Watersheds Database.

\begin{tabular}{|l|l|l|}
\cline { 2 - 3 } \multicolumn{1}{l|}{$\begin{array}{l}\text { Hydrologically defined } \\
\text { area at } 4^{\text {th }} \text { or } 5^{\text {th }} \text { field } \\
\text { scale }\end{array}$} & $\begin{array}{l}\text { Entry Form: Watershed } \\
\text { Data }\end{array}$ & $\begin{array}{l}\text { Entry Form: Watershed } \\
\text { Documents }\end{array}$ \\
\hline $\begin{array}{l}\text { Statewide or District } \\
\text { scale, or many/most of } \\
\text { state or ODF watersheds } \\
\text { included }\end{array}$ & $\begin{array}{l}\text { Entry Form: } \\
\text { District/Statewide Data }\end{array}$ & $\begin{array}{l}\text { Entry Form: } \\
\text { District/Statewide } \\
\text { Documents }\end{array}$ \\
\hline
\end{tabular}

The map attached at the end of this document shows the name and location of fifth and fourth-field watersheds, ODF districts, and ODF WAU's. It can be used to identify the location of new items in terms of the district or basin names used in the database.

After you have decided which form to use, open it by double clicking its name in the Form window of the main Access97 dialog box (see figure 2).

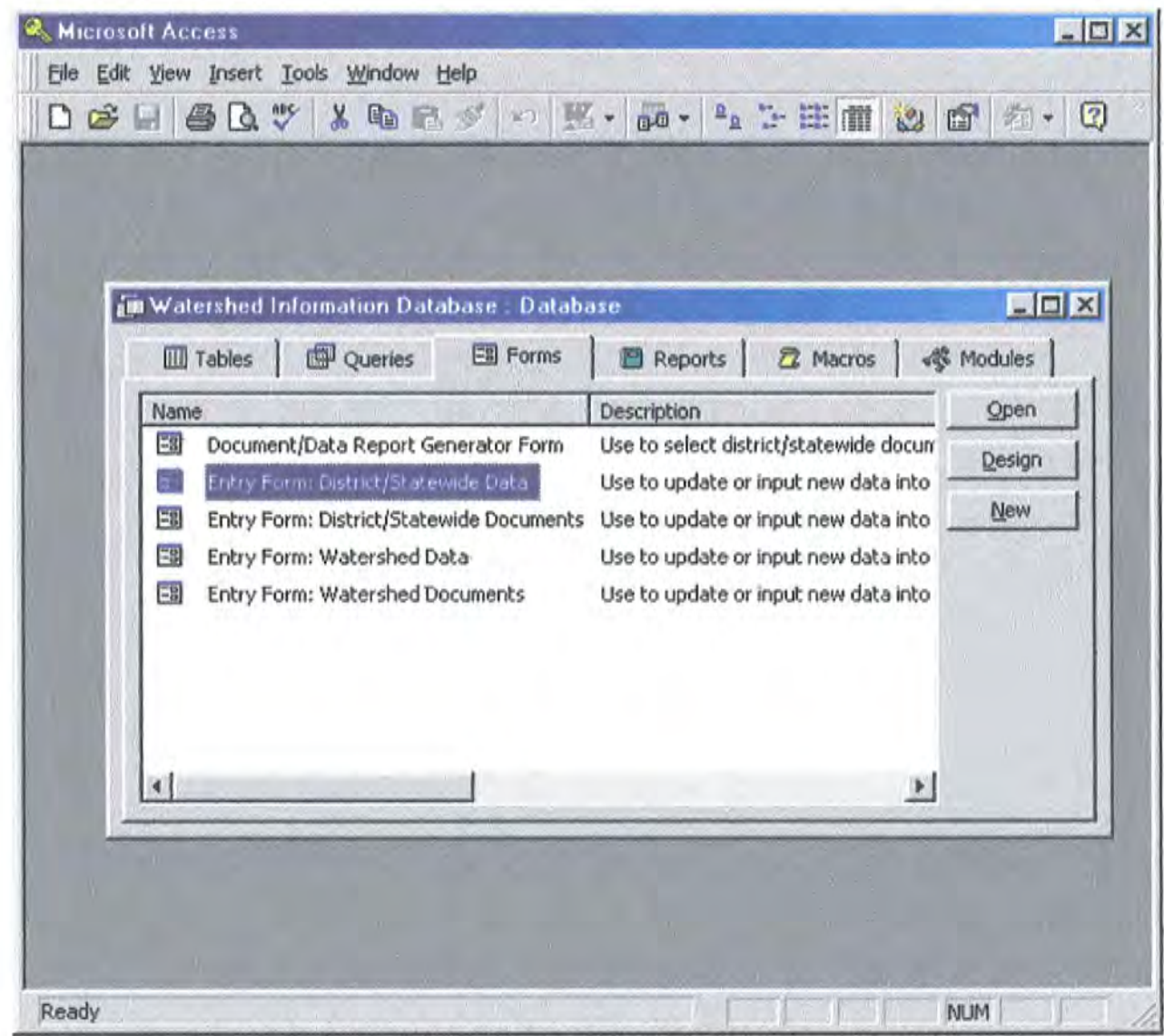

Figure 2. Access97 main dialog box showing Forms window. 
All of the forms follow the same basic layout and have the same record editing/entry tools. Figure 3 shows the interface for the District/Statewide Data Entry form. Follow the steps below to find, make changes, or add a new entry. (Caution: The forms are linked directly to the tables. Any changes made to a blank or existing record are saved as they are typed! Use the "Undo Last Entry" button to undo unwanted editing on the current record. It is advisable to create a backup copy of the database before editing or adding new data.)

\section{Entering and Editing with Forms:}

If you are not sure if an item already exists in the database or you want to check on the current status of an item begin at step One. If you know that your item is not in the database and you want to enter it as a new record skip to step Three.

1. Find entry by field: Place cursor in the field that you want to search. For most searching, editing, and new entry operations the best search field will be $<$ Title $>$ for documents and <File Name $>$ or $<$ Title $>$ for data. Press the "Find Entry By Field" button. Enter a search word and select the appropriate search criteria, and then press "Find First". Press "Find Next" several times to get an overview of all records matching your search criteria.

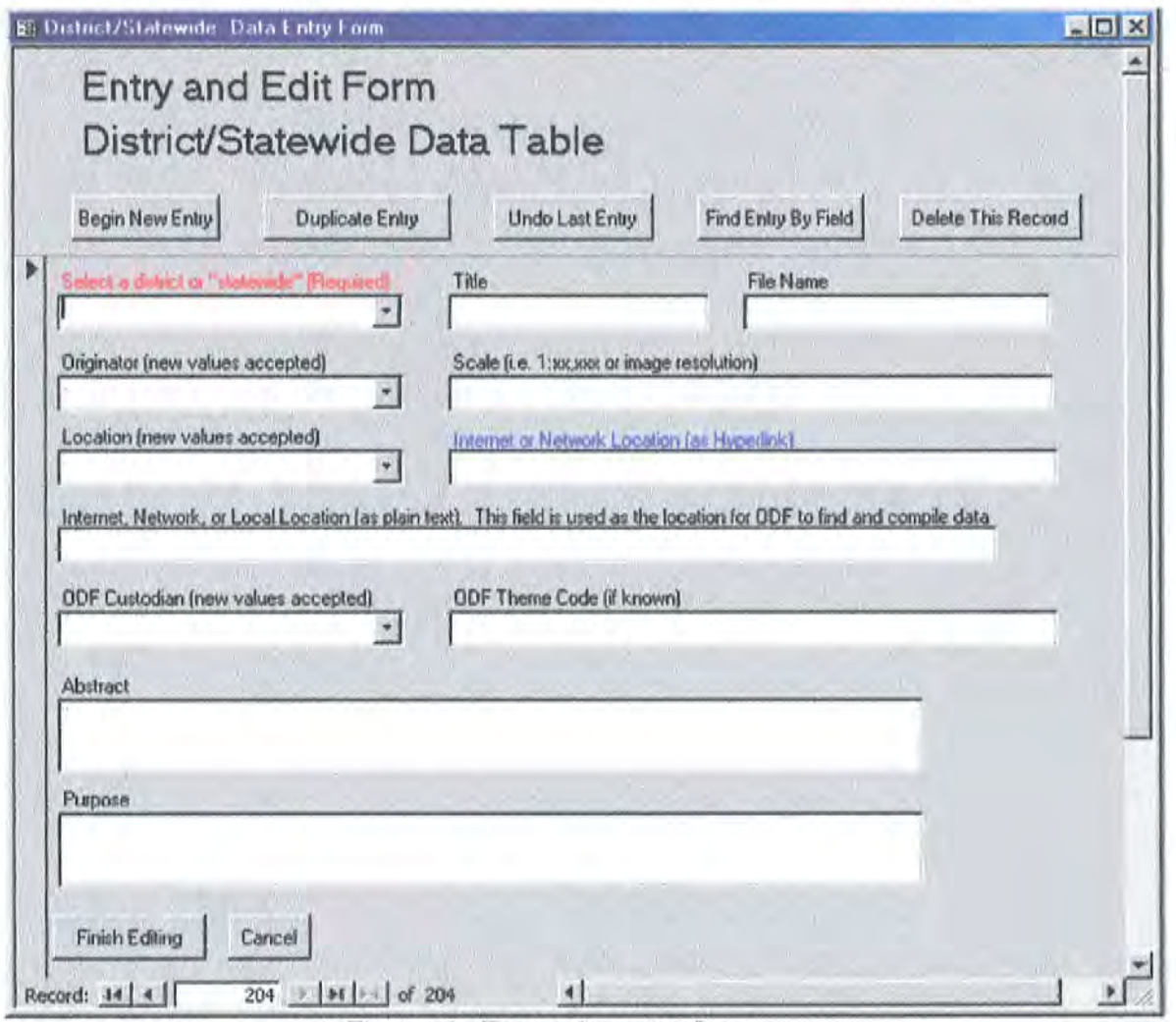

Figure 3. Example entry form. 
2. Editing Records: When you have found the record/records you want to edit, click in the field you want to change. Type or select from a dropdown list the desired changes. The database is updated as soon as you type new information or select an item from a dropdown list. If you want to undo the changes you have made to the current record press the "Undo Last Entry" button. This will only undo the changes for the current record, not previously edited records. There may exist duplicate data and/or document records relating to multiple districts or watersheds. Be sure and update information for all existing duplicate records. If you are done editing records press the "Finish Editing" button. If you wish to add an entry go on to step 3.

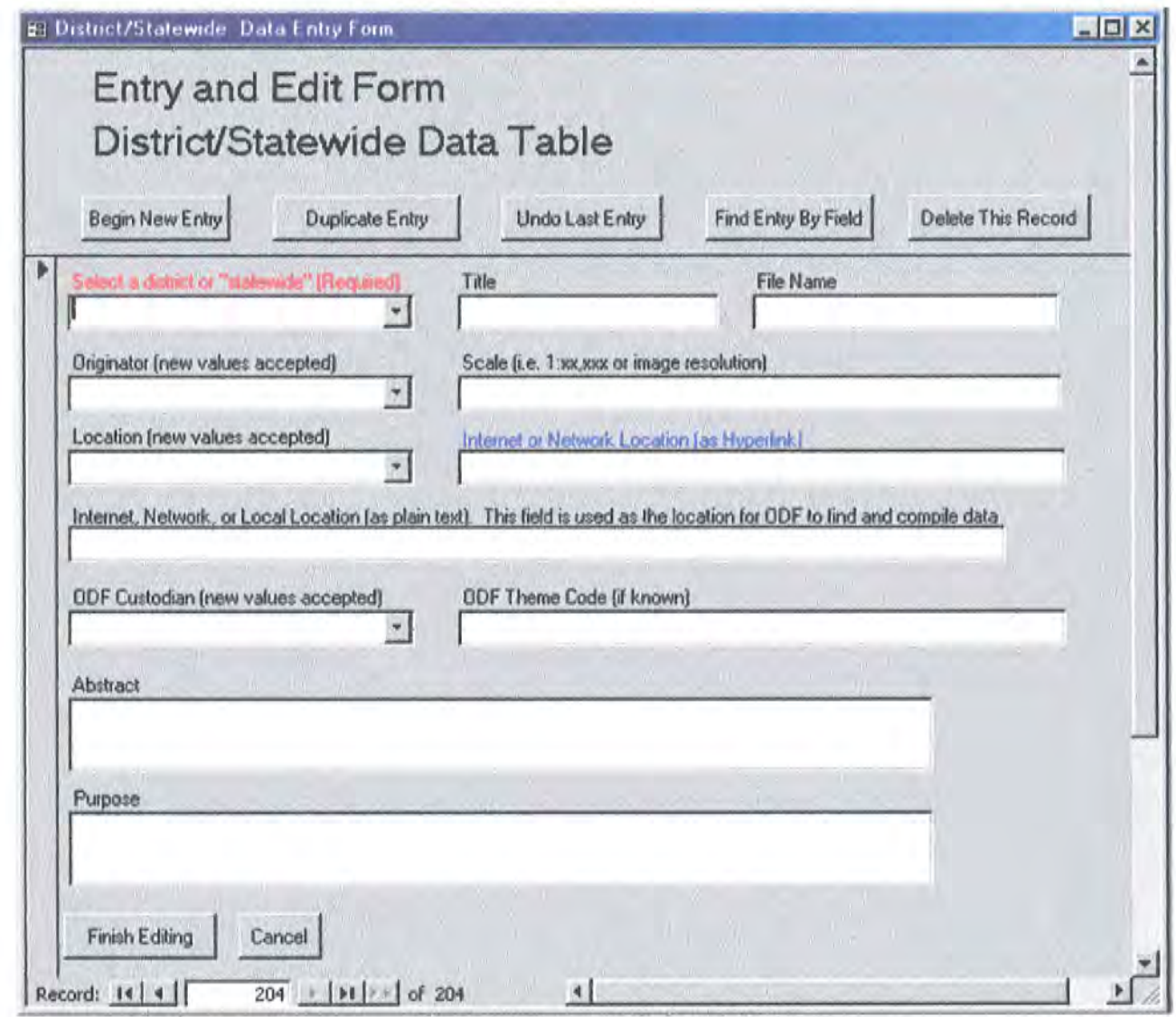

Figure 3. Example entry form.

3. Add a new entry: Before you add new records to the database make sure the record does not already exist (step 1). The form opens to a new record, so if you have just opened the form you can start entering information immediately. If you have already searched or edited records use the "Begin New Entry" button. This adds a new record to the table.

"Note" If you leave all fields blank no record will be added when you close the form. However, if you select a district or watershed, the item will be added as a new record when you close the form. 
If after entering data into the fields you decide you do not want the record saved, press "Undo Last Entry". If you have added the new information into the fields and the item only pertains to one district or one watershed then press "Finish Editing" to save your entry and exit the form. If you would like to relate the item to another district or watershed then go to step 4 . Repeat this step if you would like to add another item.

4. Duplicate an entry: The most common need to duplicate and entry is cases where the new item relates to multiple districts or watersheds. Instead of closing the form at the end of step 3, press the "Duplicate Entry" button. This will save your current entry (i.e. the record from step 3 ), and create an exact duplicate of that entry (which will be currently visible). After pressing the "Duplicate Entry" button, change the <district> or < watershed > fields (or another field if necessary) to the new name. After you have duplicated and altered the district or watershed name for all of your records, press the "Finish Editing" button to save the last record and exit the form.

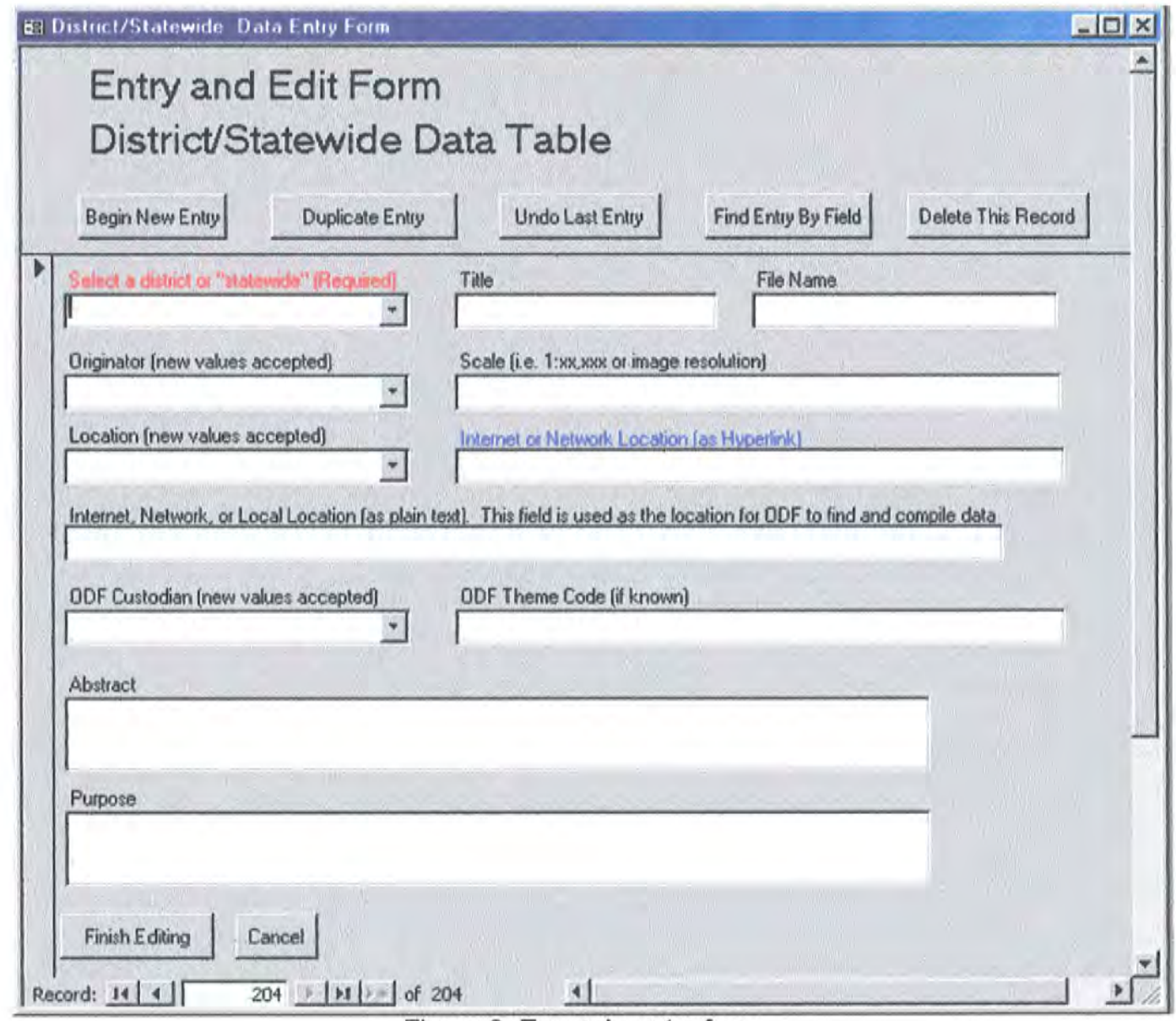

Figure 3. Example entry form. 


\section{Generating Document and Data Reports}

Reports are based on the WAU Query, which is modified by selecting a desired WAU from the Document/Data Report Generator Form shown in figure 4. Open the Document/Data Report Generator Form by double-clicking its name in the Forms window of the main Access dialog box. There are five pre-designed reports that summarize data by WAU.

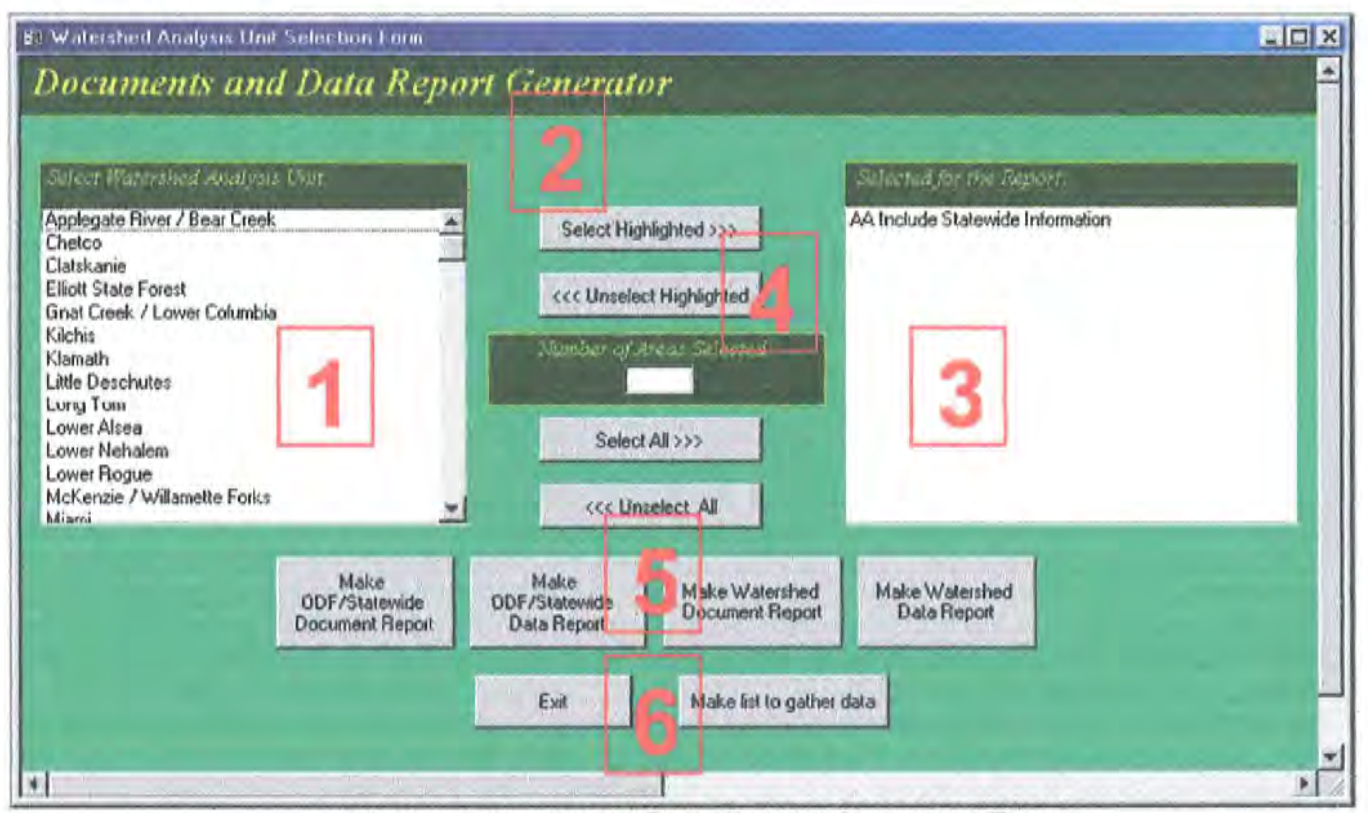

Figure 4. Document/Data Report Generator Form.

The red numbers correspond to the steps used to generate a report:

1. Use your mouse to select one or more WAU's from the Select WAU scroll list. Selected items appear highlighted in black.

2. Press the "Select Highlighted $\gg>$ " button to move the WAU name to the Selected for the Report column.

3. Make sure that the variable "AA Include Statewide Information" is in the Selected for the Report column if you want to include statewide data and documents (recommended).

4. Review the items listed in the column. Use the "<<<Unselect Highlighted" button to remove unwanted WAU's from the column.

5. Choose a report from the four report options. Each of these buttons will open a preview of the report from which you can print a copy. 
6. Click the "Make list to gather data" button to create a list of data that can be gathered. This report is a subset of the ODF/Statewide Data Report that only lists the name and location of data available from ODF. This list is useful for finding and compiling data for delivery. Once querying and reporting functions are done press the "Exit" button.

\section{Creating Reports and viewing contents of the entire database}

The whole contents of each of the four main tables may be viewed in Report form by following the steps mentioned in section 3 . Instead of selecting individual WAU's, press the "Select All >>>" button and then press the Report button of the desired table. The output will show unique records of each item in that table. The report does not show duplicate items that pertain to multiple watersheds or districts.

To see all records including duplicates that exist in a table, go to the main Access dialog box and click on the Tables tab. Double clicking on any table will open that table and allow you to browse all of the fields of every record.

\section{Updating $5^{\text {th }}$ field watersheds within Watershed Analysis Units}

At the time of writing the final location of fifth-field watersheds within larger Watershed Analysis Units has not been finalized. This section describes how to change the current groupings within the database so that the fifth-field watersheds are related to the correct WAU.

1. Open the WAU $5^{\text {th }}$ Bridge Table under the Table tab of the main Access dialog box.

2. The Watershed column is the name of fifth-field watersheds. The Analysis Unit column is the name of the WAU for which the fifth-field watershed is currently related. Find the fifth-field watershed whose WAU you want to change.

3. In the Analysis Unit column, click in the field of the desired watershed and select a new WAU name from the drop-down list. The change is saved automatically, all future reports generated from the newly chosen WAU will include documents and data related to that fifth-field watershed. 


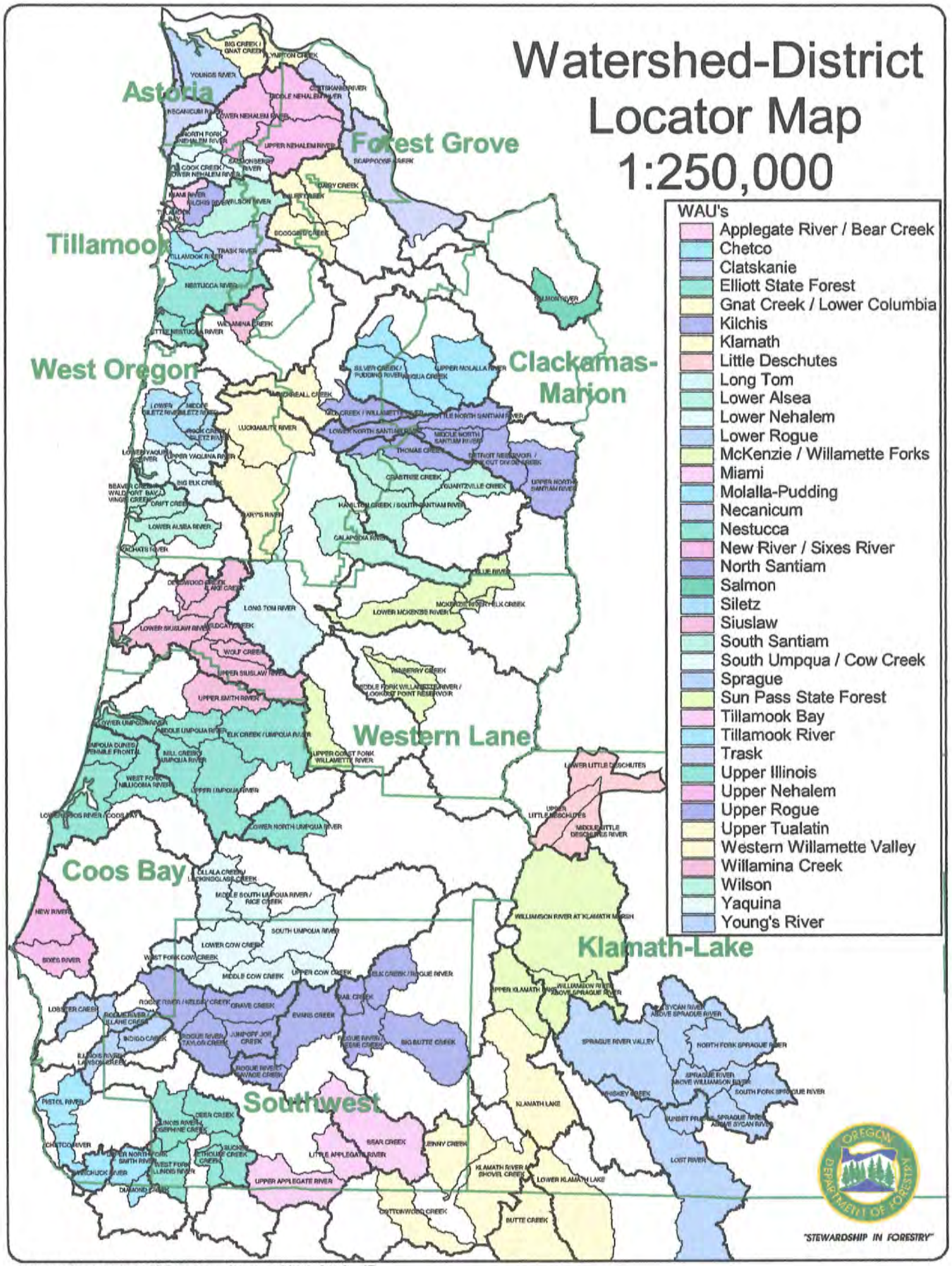

Oregon Department of Forestry. October 22nd, 2002. JD 